\title{
Comparative genomic analysis of four representative plant growth-promoting rhizobacteria in Pseudomonas
}

\author{
Xuemei Shen, Hongbo Hu, Huasong Peng, Wei Wang and Xuehong Zhang*
}

\begin{abstract}
Background: Some Pseudomonas strains function as predominant plant growth-promoting rhizobacteria (PGPR). Within this group, Pseudomonas chlororaphis and Pseudomonas fluorescens are non-pathogenic biocontrol agents, and some Pseudomonas aeruginosa and Pseudomonas stutzeri strains are PGPR. P. chlororaphis GP72 is a plant growth-promoting rhizobacterium with a fully sequenced genome. We conducted a genomic analysis comparing GP72 with three other pseudomonad PGPR: P. fluorescens Pf-5, P. aeruginosa M18, and the nitrogen-fixing strain P. stutzeri A1501. Our aim was to identify the similarities and differences among these strains using a comparative genomic approach to clarify the mechanisms of plant growth-promoting activity.

Results: The genome sizes of GP72, Pf-5, M18, and A1501 ranged from 4.6 to 7.1 M, and the number of protein-coding genes varied among the four species. Clusters of Orthologous Groups (COGs) analysis assigned functions to predicted proteins. The COGs distributions were similar among the four species. However, the percentage of genes encoding transposases and their inactivated derivatives (COG L) was 1.33\% of the total genes with COGs classifications in A1501, $0.21 \%$ in GP72, $0.02 \%$ in Pf-5, and $0.11 \%$ in M18. A phylogenetic analysis indicated that GP72 and Pf-5 were the most closely related strains, consistent with the genome alignment results. Comparisons of predicted coding sequences (CDSs) between GP72 and Pf-5 revealed 3544 conserved genes. There were fewer conserved genes when GP72 CDSs were compared with those of A1501 and M18. Comparisons among the four Pseudomonas species revealed 603 conserved genes in GP72, illustrating common plant growth-promoting traits shared among these PGPR. Conserved genes were related to catabolism, transport of plant-derived compounds, stress resistance, and rhizosphere colonization. Some strain-specific CDSs were related to different kinds of biocontrol activities or plant growth promotion. The GP72 genome contained the cus operon (related to heavy metal resistance) and a gene cluster involved in type IV pilus biosynthesis, which confers adhesion ability.

Conclusions: Comparative genomic analysis of four representative PGPR revealed some conserved regions, indicating common characteristics (metabolism of plant-derived compounds, heavy metal resistance, and rhizosphere colonization) among these pseudomonad PGPR. Genomic regions specific to each strain provide clues to its lifestyle, ecological adaptation, and physiological role in the rhizosphere.
\end{abstract}

Keywords: Plant growth-promoting rhizobacteria, Pseudomonad, Comparative genomics, Environmental adaptability, Rhizosphere colonization, Biocontrol activity

\footnotetext{
* Correspondence: xuehzhang@sjtu.edu.cn

State Key Laboratory of Microbial Metabolism, School of Life Sciences and Biotechnology, Shanghai Jiao Tong University, 800 Dongchuan Road, Shanghai 200240, People's Republic of China
} 


\section{Background}

Pseudomonas (sensu stricto) is a diverse genus that occupies many different niches and exhibits versatile metabolic capacity [1]. A number of pseudomonad strains function as plant growth-promoting rhizobacteria (PGPR). Such strains can protect plants from various soilborne pathogens and/or stimulate plant growth [2]. For example, Pseudomonas chlororaphis and Pseudomonas fluorescens are non-pathogenic biocontrol agents, while several strains of Pseudomonas aeruginosa and Pseudomonas stutzeri show strong plant growth-promoting activities. Some characteristic features associated with plant growth promotion have been studied at the molecular level. For example, effective PGPR show sufficient colonization of the rhizosphere [3,4]. Moreover, PGPR have certain biocontrol activities; for example, they can produce antibiotics that prevent infection by plant pathogens [2]. Such antibiotics include phenazine derivatives [5-7], pyoluteorin (Plt) [8,9], pyrrolnitrin (Prn) [10], hydrogen cyanide (HCN) [11], and so on. Some rhizobacteria directly promote plant growth in the absence of pathogens [12]. However, a comprehensive analysis of the characteristics of PGPR among different Pseudomonas species using a comparative genomics approach has not been reported yet.

Comparative genomics has emerged as a powerful tool to identify functionally important genomic elements [13-15]. As more and more genomic information becomes available, the development of genomic technologies can provide further insights into essential life processes [16]. As of March 2012, the complete genomic sequences of strains representing the following Pseudomonas species were available: the rhizobacteria $P$. fluorescens [14,17], $P$. stutzeri [18], and Pseudomonas putida [15,19,20], and the pathogens $P$. aeruginosa [21,22], Pseudomonas syringae [23], and Pseudomonas entomophila [24]. Genomic information for $P$. chlororaphis, which plays an important role in suppressing pathogens and stimulating plant growth [3,25-27], was first reported by our group [28].

P. chlororaphis GP72 (hereafter, GP72) was isolated from the rhizosphere of green pepper in China. This strain shows broad antagonistic activities [29]. It completely suppresses the phytopathogens Coletotrichum lagenarium, Pythium ultimum, Sclerotinia sclerotiorum, Fusarium oxysporum f. sp. cucumerinum, Carposina sasakii, and Rhizoctonia solani [7]. In vitro screening and in vivo genetic engineering experiments showed that GP72 can produce two phenazine derivatives, phenazine-1-carboxylic acid (PCA) and 2-hydroxyphenazine (2-OH-PHZ), which have strong fungicidal activities [30]. It also produces other secondary metabolites including $\mathrm{HCN}$, indole-3-acetic acid (IAA), and siderophores, contributing to rhizosphere adaptability [7]. P. fluorescens Pf-5 (hereafter, Pf-5) was isolated from the rhizosphere of cotton and is able to suppress damping-off caused by P. ultimum
[8]. As a well-recognized biocontrol agent, Pf-5 produces a spectrum of antibiotics including Prn, Plt, and 2,4diacetylphloroglucinol (DAPG) [8,31], and two siderophores, pyoverdine (Pvd) and pyochelin (Pch). $P$. aeruginosa M18 (hereafter, M18) was isolated from the rhizosphere of sweet melon. It produces both PCA and Plt, which show strong antifungal activities [22,32], and it shows biocontrol activity in the rhizosphere niche [33]. Most $P$. aeruginosa strains are opportunistic pathogens, including the first-sequenced strain, $P$. aeruginosa PAO1 [21,34,35]. P. stutzeri A1501 (hereafter, A1501), which belongs to the nonfluorescent Pseudomonas group, was isolated from the rhizosphere of rice based on its nitrogen-fixation capacity [36,37]. A1501 has been commercialized for use as a crop inoculant in China. Genetic information for A1501 has provided insights into the mechanisms of its nitrogen-fixation ability and environmental adaptability, such as its ability to mineralize aromatic compounds [18,38].

To identify the shared characteristics of pseudomonad PGPR, we compared genomic information for GP72 with those of three other representative pseudomonad PGPR: the biological control agent Pf-5, the rhizobacterium M18, and the nitrogen-fixing strain A1501. There were 602 genes conserved among the four species. Comparison among these PGPR also revealed previously unknown common traits related to plant growth promotion. This comparative genomics analysis of different PGPR provides information about the genetic basis of diversity and adaptation. The results of this study also provide foundation knowledge to improve and exploit the plant growthpromoting activities of PGPR in agricultural applications via molecular techniques.

\section{Results and discussion}

\section{General genome features and comparative genomics}

The general features of the four PGPR genomes are summarized in Table 1. The assembled genome of GP72 had approximately 270 -fold sequence coverage [28], with putative functions assigned to $83 \%$ of the genes. It is reasonable to assume that the vast majority of genes are important for cell metabolism. GP72, Pf-5, M18, and A1501 showed a wide range of genome sizes, ranging from 4.6 to $7.1 \mathrm{M}$, resulting in different numbers of proteincoding genes (Table 1). The genome sequences and additional information related to each predicted gene, such as gene product annotation, KEGG orthology, gene ontology, and predicted subcellular location are available on the IMG database (https://img.jgi.doe.gov/cgi-bin/er/main.cgi) [39]. Predicted proteins were functionally categorized using the COGs database [40], and COGs categories were compared among the genomes of GP72, Pf-5, M18, and A1501 (Figure 1). The COGs showed similar distributions among the four strains, except for the COGs $\mathrm{K}$ and L, 
Table 1 General genome features of the four studied pseudomonad PGPR

\begin{tabular}{|c|c|c|c|c|}
\hline & GP72 & Pf-5 & M18 & A1501 \\
\hline Size (base pairs) & $6,663,241$ & $7,074,893$ & $6,327,754$ & $4,567,418$ \\
\hline $\mathrm{G}+\mathrm{C}$ content $(\%)$ & $63.13 \%$ & $63.30 \%$ & $66.50 \%$ & $63.88 \%$ \\
\hline Protein-coding genes & 6091 & 6142 & 5690 & 4135 \\
\hline No. of protein-coding genes with function prediction & $5062(83.11 \%)$ & $4492(73.14 \%)$ & $4115(72.32 \%)$ & $3227(78.04 \%)$ \\
\hline No. of protein-coding genes without function prediction & $16.89 \%$ & $26.86 \%$ & $27.68 \%$ & $21.96 \%$ \\
\hline No. of protein-coding genes connected to KEGG Orthology & $53.77 \%$ & $51.84 \%$ & $53.95 \%$ & $57.61 \%$ \\
\hline No. of protein-coding genes with COGs & $82.66 \%$ & $79.27 \%$ & $83.88 \%$ & $80.58 \%$ \\
\hline No. of protein-coding genes coding signal peptides & $24.48 \%$ & $24.28 \%$ & $25.17 \%$ & $22.03 \%$ \\
\hline No. of protein-coding genes coding transmembrane proteins & $23.71 \%$ & $23.58 \%$ & $23.71 \%$ & $24.76 \%$ \\
\hline RNA genes & 85 & 115 & 79 & 102 \\
\hline rRNA genes (5S rRNA, 165 rRNA, 235 rRNA) & $4(2,1,1)$ & $16(6,5,5)$ & $13(5,4,4)$ & $13(4,4,5)$ \\
\hline tRNA genes & 61 & 71 & 61 & 61 \\
\hline Other RNA genes & 20 & 28 & 5 & 28 \\
\hline Conserved CDS & 602 & 558 & 572 & 545 \\
\hline Strain-specific CDS & 994 & 1116 & 1351 & 1195 \\
\hline
\end{tabular}

Gene annotations and comparisons were obtained from IMG database [39]. Numbers of conserved and specific genes in each strain determined by comparison to other PGPR genomes. Genes with homology $(\mathrm{H})$ values less than 0.42 and more than 0.81 were arbitrarily defined as specific and conserved, respectively.

which were quite different in A1501 compared with the other strains. The percentage of genes with COG K annotations, representing transcription clusters, was lower in A1501 than in the other three strains, mainly because it contained a smaller proportion of genes encoding transcriptional regulators. COG $\mathrm{L}$ represents proteins with functions in replication, recombination, and repair. There were 50 genes encoding transposases and their inactivated derivatives in A1501 (approximately 1.33\% of the total genes with COG annotations), compared with $0.21 \%$ in GP72, $0.02 \%$ in Pf-5, and $0.11 \%$ in M18. The large number of transposases in A1501 indicated that this strain would be more suitable for transposition, providing clues to the genetic diversity within this species and its adaptability to changes in growth conditions.

Global alignments provide a powerful tool to identify conserved and specific regions in the genome, which can reveal similar biological behaviors or adaptations to specific niches. We conducted BLASTN analysis using an online version of the Artemis Comparison Tool (WebACT) [41], comparing GP72, Pf-5, and M18 (Figure 2). We excluded A1501 from this analysis, since the alignment analysis showed very low synteny (data not shown). According to alignments at current assemblies, the extent of conservation of regions among the different species of Pseudomonas was difficult to visualize by ACT, mainly because of multiple chromosomal rearrangements. Nevertheless, the genomes of Pf-5 and GP72 showed many regions with conserved sequences and conserved gene order, except for 10 major inversions. BLAST atlas, which provides a quick overview of genomic regions of gene conservation across many genomes [42], was used to compare the reference genome of GP72 to the other three query genomes (Figure 3).

We established a phylogenetic tree of completely sequenced pseudomonads based on two housekeeping genes (gyrB and rpoD) (Figure 4). The tree showed that GP72 was most closely related to P. fluorescens, and was more closely related to $P$. aeruginosa M18 than to other opportunistic pathogenic strains of $P$. aeruginosa. This was probably because the rhizosphere-originated M18 strain has evolved strain-specific genomic features, which benefit its environmental adaptability and competitiveness under certain conditions in the rhizosphere niche.

An in silico subtractive hybridization analysis using the mGenomeSubtractor web server identified specific and conserved proteins. In this analysis, proteins with homology $(\mathrm{H})$ values of less than 0.42 or more than 0.81 are defined arbitrarily as specific or conserved, respectively [43]. The BLASTP-based homology value distribution of 6091 predicted CDSs from P. chlororaphis GP72 was individually compared with those of the other three subject genomes (Figure 5A) to determine the degree of protein conservation between GP72 and each of the other genomes. Among the genes encoded in the GP72 genome, 3,544 had counterparts in the genome sequence of Pf- 5 . There were 999 genes conserved among the genomes of GP72, Pf-5, and M18. Comparison among GP72 and all of the other three strains (Pf-5, M18, and A1501) revealed 602 homologous genes and 994 CDSs that were strainspecific to GP72 (Figure 5B). The number of homologs in each genome is shown in Figure 4. In addition, GP72 contained 463 CDSs that were identified as strain-specific $\left(\right.$ E-value $<10^{-5}$ ) when its genome was compared with those 


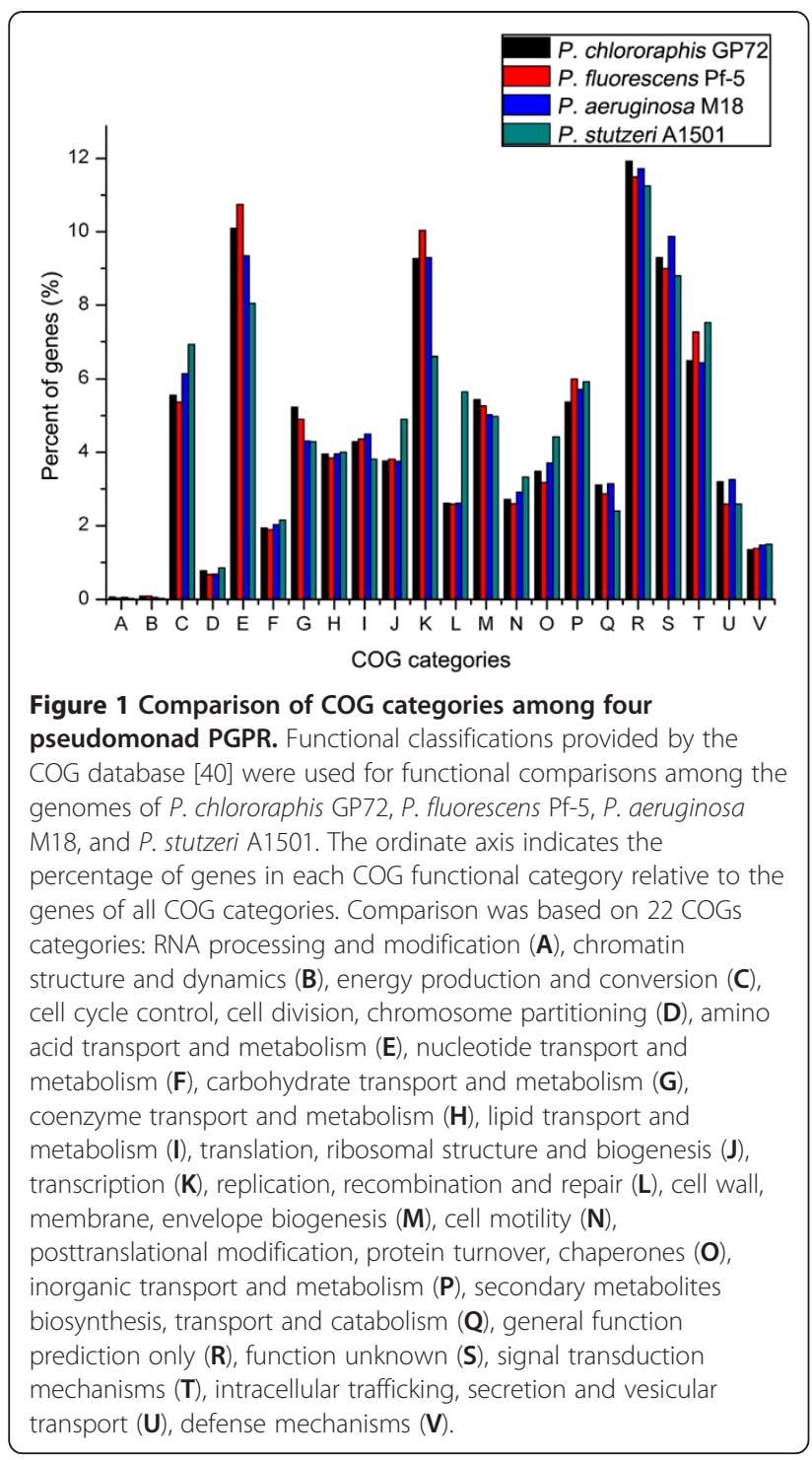

of 27 other completely sequenced Pseudomonas strains. Further analyses of these strain-specific CDS may provide clues to the phenotype and the specific environmental adaptations of each strain.

\section{Environmental adaptability Catabolism}

PGPR can use a wide range of nutrients to colonize the rhizosphere successfully. The central metabolic pathways in GP72, such as the Entner-Doudoroff pathway, the pentose phosphate pathway, and the tricarboxylic acid cycle, are consistent with those reported for other Pseudomonas species [44]. Like other Pseudomonas strains, GP72 lacks 6-phosphofructokinase; therefore, it may not have a functional Embden-Meyerhof pathway. The genomes of GP72, Pf-5, M18, and A1501 contained genes encoding a fructose-specific IIA component, I-phosphofructokinase.
This enzyme is involved in the fructose dissimilation pathway, catalyzing the conversion of fructose to fructose-1,6diphosphate [45].

PGPR have a variety of genes related to catabolism and transport of plant-derived compounds, such as amino acids, fatty acids, nucleotides, organic acids, carbohydrates, and other exudates [46,47]. Amino acids are one of the major components of root exudates. Accordingly, there were at least 500 genes involved in amino acid transport and metabolism in the genomes of GP72, Pf-5, and M18, and more than 300 in the genome of A1501.

The ability to catabolize aromatic compounds in exudates is one strategy that could confer a selective advantage in the rhizosphere environment. Oxygenases play key roles in the chemical transformation of recalcitrant organic compounds [48,49]. P. putida modifies diverse aromatics to common intermediates, which feed into central pathways [50]. For example, P. putida KT2440 is able to use aromatic compounds including benzoate, phenylacetate, tyrosine, and vanillate, as the sole carbon and energy source [51]. There were 21 genes encoding dioxygenases (DOs) in the genome of GP72, 22 in M18, 21 in Pf-5, and 9 in A1501. The DOs in GP72, including benzoate 1,2-dioxygenase, anthranilate 1,2-dioxygenase, protocatechuate 3,4-dioxygenase, and catechol 1,2dioxygenase, were related to degradation of aromatic compounds. We compared the degradation pathways of aromatic compounds, including the three main pathways (Table 2) and several peripheral pathways, among the four species (Additional file 1).

Genes encoding components of the 3-oxoadipate pathway, which is common in soil and plant-associated microorganisms [52], were present in the genomes of all four PGPR analyzed in this study. The pathway has two branches: one converting catechol and the other converting protocatechuate. Both branches produce two tricarboxylic acid cycle intermediates. Based on the comparative genomic analysis, the former branch may derive from the degradation of tryptophan [53], benzoate [54], salicylate [55], phenol [56,57], and so on, while the protocatechuate branch is generated from 4-hydroxybenzoate [58], and numerous lignin monomers such as vanillate [59] and quinate [60]. Analyses of aromatic compound catabolism not only reveal the broad metabolic activities of PGPR, but also provide insights into mediating the production of useful secondary metabolites such as phenazine [61], pyocyanin (PYO) [62], and C-1027 [63].

Some bacteria and fungi degrade tyrosine (Tyr) via the central intermediate homogentisate (2,5-dihydroxyphenylacetate). The reaction proceeds with conversion of Tyr into 4-hydroxyphenylpyruvate (HPP) (by tyrosine aminotransferase), and then formation of homogentisate (by HPP dioxygenase), which is degraded via the homogentisate central pathway [64]. The central pathway 


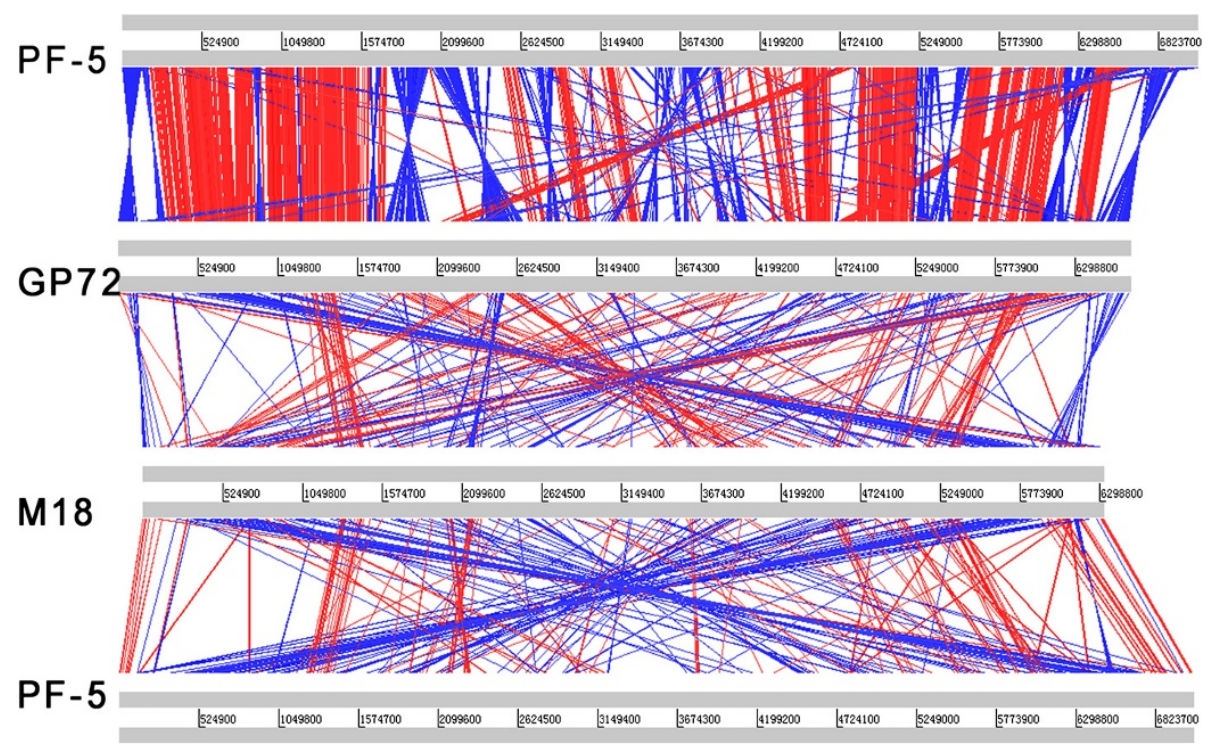

Figure 2 Comparison of chromosome structures among genome sequences of pseudomonad PGPR. Pair-wise alignments between genome sequences of $P$. fluorescens Pf-5, P. chlororaphis GP72, and P. aeruginosa M18 were performed using WebACT [41]. Red bars indicate collinear regions of similarity; blue bars represent regions of similarity that have been inverted in one of the two genomes. Only matches larger than $1 \mathrm{~kb}$ are shown.

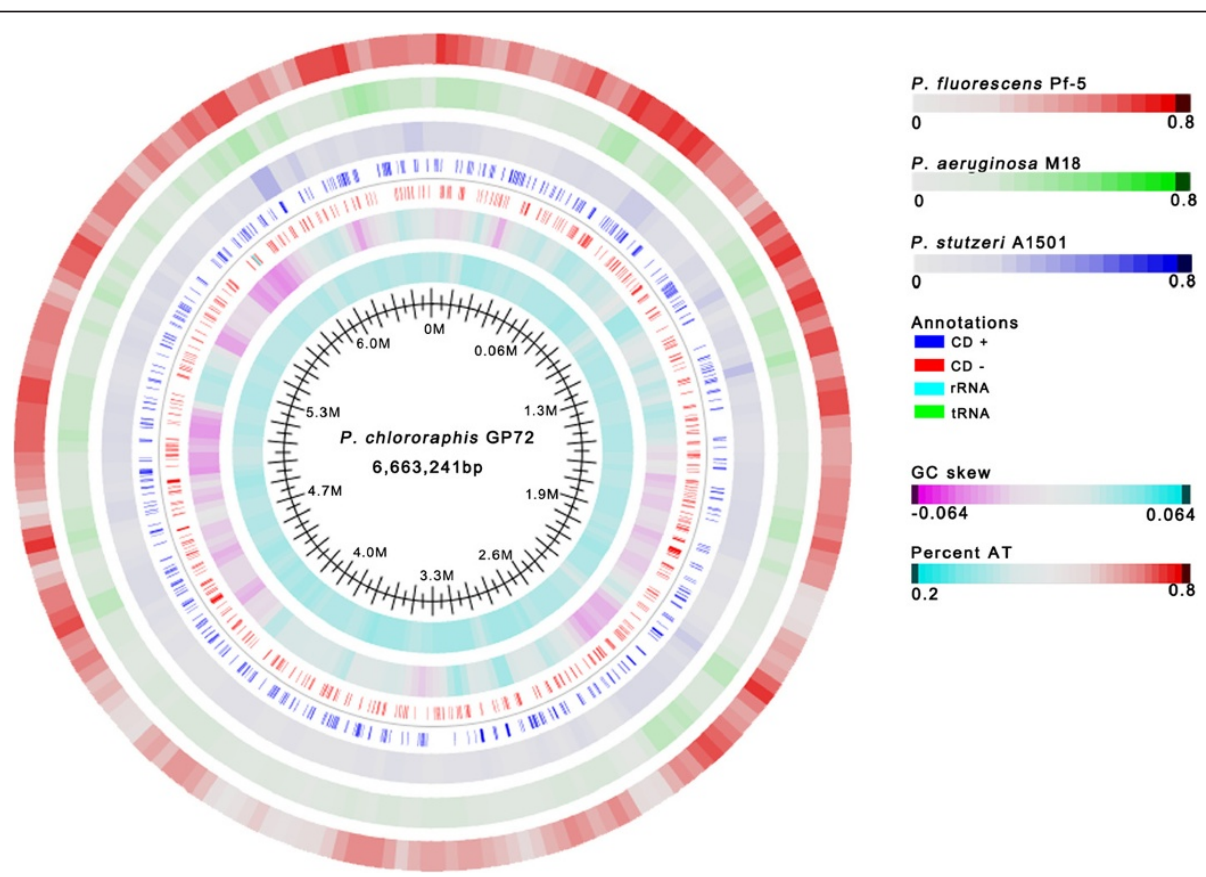

Figure 3 BLAST atlas diagram showing homology among pseudomonad PGPR. Comparisons between P. chlororaphis GP72 and three other pseudomonad PGPR. Colors indicate strains, as follows (starting from the outermost line): red, P. fluorescens Pf-5 (line 1); green, P. aeruginosa M18 (line 2); blue, P. stutzeri A1501 (line 3). Lack of color indicates that genes at that position in GP72 were absent from genome of strain in that line. Predicted CDSs of reference genome (GP72) on plus and minus strand are shown as blue and red blocks; rRNA genes are shown in green, tRNA genes are shown in turquoise. GC skew (line 6) and percent AT (line 7) are also shown. 


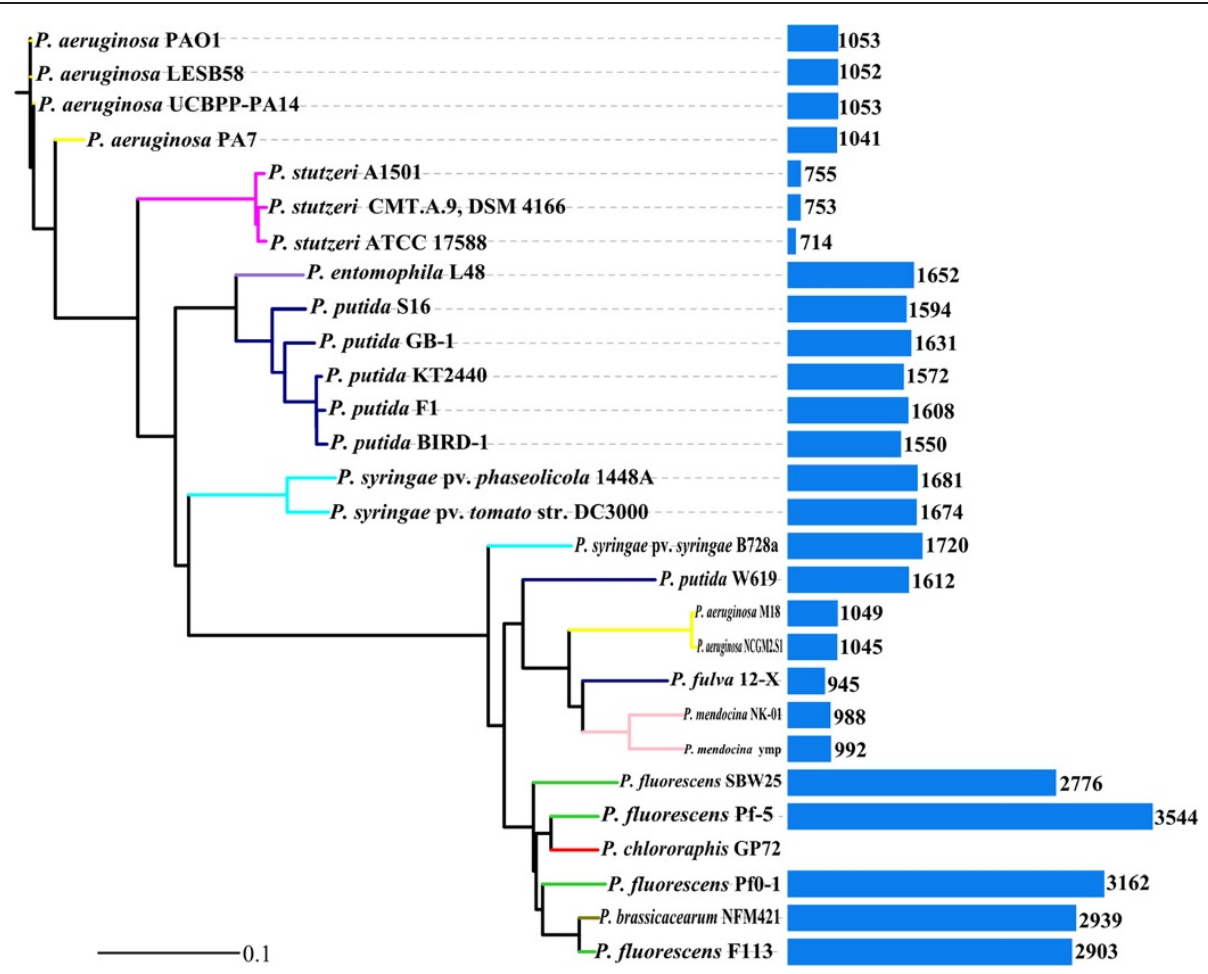

Figure 4 Phylogenetic relationships among completely sequenced Pseudomonas species. Phylogenetic tree for members of the genus Pseudomonas was constructed based on aligned concatenated sequences of gyrB and rpoD using the neighbor-joining method with 1000 bootstrap replicates. Analysis was carried out using Phylip 3.67 software and the tree was plotted using iTOL software. Colors on the phylogenetic tree indicate membership in Pseudomonas phylogenetic groups according to NCBI taxonomy. Completely sequenced species in the genus Pseudomonas include P. aeruginosa (yellow), P. brassicacearum (olive), P. entomophila (purple), P. fluorescens (green), P. fulva (blue),

P. mendocina (pink), P. putida (navy), P. stutzeri (magenta), and P. syringae (cyan). In this research, the tree branch of $P$. chlororaphis, whose draft genome sequence was reported recently, is shown in red. Bar chart associated with nodes indicates numbers of genes conserved between GP72 and the corresponding organism. Conserved genes were determined using mGenomeSubtractor.

involves three enzymes: homogentisate 1,2-dioxygenase (HmgA), fumarylacetoacetate hydrolase ( $\mathrm{HmgB})$, and maleylacetoacetate isomerase $(\mathrm{HmgC})$, and yields fumarate and acetoacetate [65]. The comparative genomic analysis indicated that GP72, Pf-5, and M18 could degrade Tyr via the homogentisate pathway. Some Gram-positive bacteria can convert Tyr into homoprotocatechuate (3,4dihydroxyphenylacetate), rather than homogentisate, producing pyruvate and succinate [66,67]. A variety of microorganisms contain 3,4-dihydroxyphenylacetate 2,3dioxygenases (HPCD) $[68,69]$, such as Fe(II) (HPCD) and $\mathrm{Mn}$ (II) (MndD). These enzymes contain different active sites resulting in different structures and HPCD activities [70,71]. The annotated amino acid sequence of the HPCD from GP72 exhibited 63-64\% identities with those of the corresponding enzymes from Escherichia coli [68] and Klebsiella pneumonia [69]. Further research is required to characterize the activities of HPCD in different Pseudomonas species.

In a few organisms, phenylethylamine, an intermediate of phenylalanine degradation, can be converted into phenylacetaldehyde by quinohemoprotein amine dehydrogenase, and then transformed into phenylacetate by phenylacetaldehyde dehydrogenase [72-74]. The corresponding genes were predicted in the genomes of GP72 and Pf-5, but they were not located in a single operon.

Phenylacetyl-CoA is derived from various substrates such as phenylalanine, lignin-related aromatic compounds, and environmental contaminants, and can be degraded to succinyl-CoA and acetyl-CoA [75,76]. Based on the genomic comparison at the $60 \%$ identity threshold, we found that the phenylacetate degradation pathway was present in GP72 and Pf- 5 . However, this pathway was not detected in M18 or A1501 at the same identity level, indicating potentially different evolutionary directions in specific niches.

Five putative phenylpropionate dioxygenases and related ring-hydroxylating dioxygenases of unknown specificity can also participate in aromatic compound catabolism [77].

Plant-derived substances not only serve as important carbon and energy sources for rhizosphere bacteria, but also influence bacterial behaviors [78,79]. For example, the ratio of rhizospheric carbon:nitrogen $(\mathrm{C}: \mathrm{N})$ can alter the nutritional status of Rhizoctonia solani, making the fungus a pathogen [80]. Tomato root exudates promote 


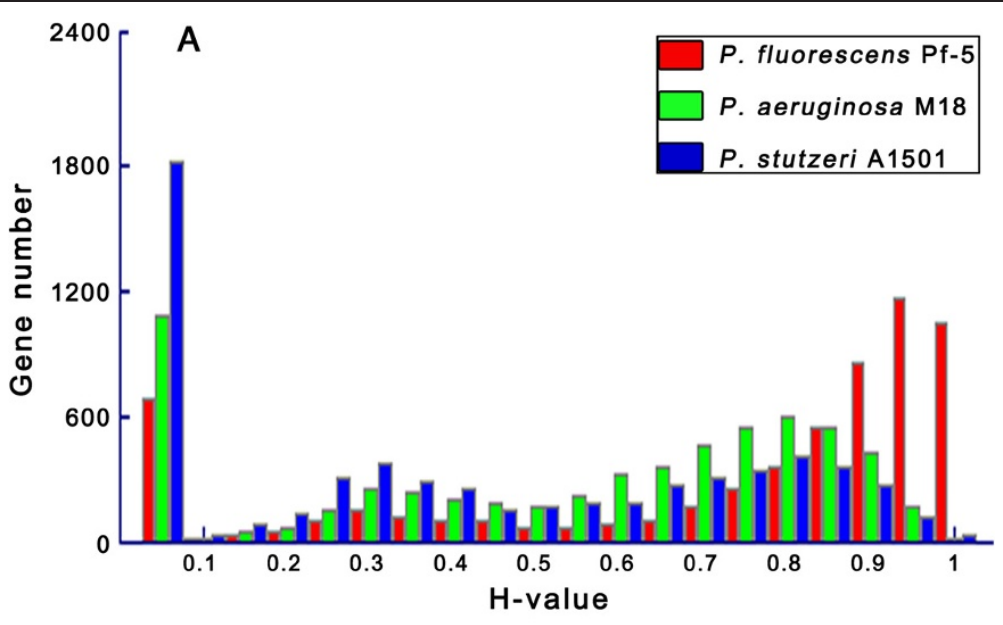

B

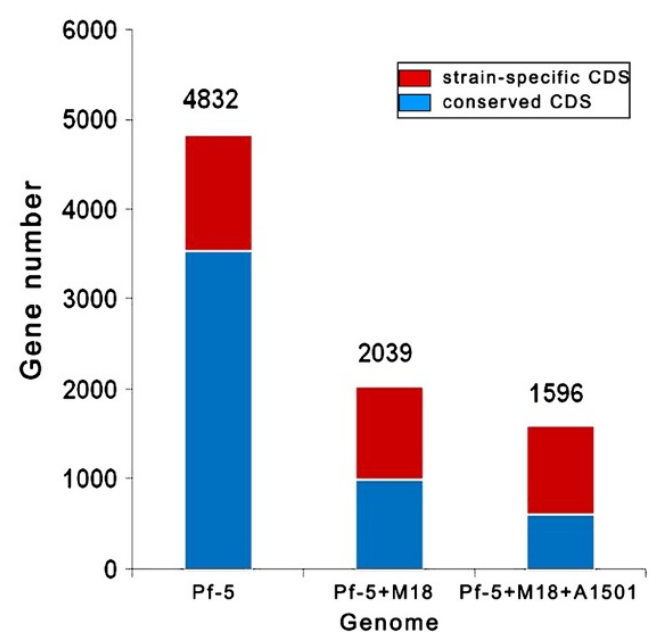

Figure 5 Homology analysis between P. chlororaphis GP72 genome and three subject genomes. The mGenomeSubtractor arbitrarily defines CDSs with homology $(\mathrm{H})$ values less than 0.42 as strain-specific, and those with $\mathrm{H}$ values greater than 0.81 as conserved [43].

(A) Histogram of BLASTP-based homology value distribution of 6091 predicted CDSs from P. chlororaphis GP72 compared individually with those of three other genomes: P. fluorescens Pf-5, P. aeruginosa M18, and P. stutzeri A1501. (B) Numbers of conserved and specific genes in GP72 compared with three other PGPR strains. Total numbers of conserved and specific genes are shown above columns.

germination of spores of the tomato root pathogen $F$. oxysporum f. sp. radicis-lycopersici, whereas the biocontrol agent P. fluorescens WCS365 delays this process [81]. Microarray analyses showed that root exudates affected the transcriptome of $P$. aeruginosa PAO1 by influencing genes encoding enzymes related to alginate biosynthesis and twitching motility [82]. Therefore, the production of plant-derived exudates could alter the composition of rhizospheric microorganism communities. Further research is required to investigate the molecular mechanisms underlying changes in community structure.

\section{Transport}

Consistent with the abundance of genes related to metabolism of plant-derived substances, the four PGPR contained many putative transport genes related to substrate uptake and excretion (Table 3). GP72 and Pf-5 contained similar numbers of transport genes. In bacteria, secretion systems play an important role in transport or translocation of effectors for adaptation to their natural surroundings. The genomes of these four PGPR contained type I, type II, type IV, type V, and type VI secretion systems, as well as the chaperone-usher secretion system and the twin-arginine translocation system. M18 also contained the Type III (flagellar/pathogenesis) secretion system, a key virulence factor in pathogenic Pseudomonas [83].

\section{Defense pathways}

Previous studies showed that GP72 resists streptomycin up to a concentration of $100 \mu \mathrm{g} \mathrm{ml}^{-1}$, and tolerates salt ( $5 \% \mathrm{NaCl}$ solution). Both of these resistances are stronger than those of $P$. chlororaphis strain 30-84 [7]. 
Table 2 Comparison of putative genes related to main pathways for central aromatic catabolism among pseudomonad PGPR

\begin{tabular}{llll}
\hline & & Homologs ${ }^{a}$ in PGPR \\
\hline Gene & Product name & GP72 ORF & Pf-5 ORF \\
& & M18 ORF & A1501 ORF \\
& ID MOK_0 & ID PFL_ ID PAM18_ ID PST_
\end{tabular}

3-oxoadipate ( $\beta$-ketoadipate) pathway

Catechol degradation III (ortho-cleavage pathway) to 3-oxoadipate enol-lactone

$\begin{array}{ll}\text { catA } & \text { catechol 1,2-dioxygenase [EC:1.13.11.1] } \\ \text { catC } & \text { muconolactone D-isomerase [EC:5.3.3.4] } \\ \text { catB } & \text { muconate cycloisomerase [EC:5.5.1.1] } \\ \text { catR } & \text { transcriptional regulator [COG0583] }\end{array}$

Protocatechuate degradation II (ortho-cleavage pathway) to 3-oxoadipate enol-lactone
pcaH protocatechuate 3,4-dioxygenase, beta subunit [EC:1.13.11.3]

$\mathrm{pcaH}$ protocatechuate 3,4-dioxygenase, beta subunit [EC:1.13.11.4]

pcaQ LysR family transcriptional regulator, pca operon transcriptional activator [KO:K02623]

$\mathrm{pcaH}$ protocatechuate 3,4-dioxygenase, beta subunit [EC:1.13.11.3]

$p c a G$ protocatechuate 3,4-dioxygenase, alpha subunit [EC:1.13.11.3]

pcaT MFS transporter, MHS family, dicarboxylic acid transporter PcaT [KO:K02625]

pcaB 3-carboxy-cis,cis-muconate cycloisomerase [EC:5.5.1.2]

pcaC 4-carboxymuconolactone decarboxylase [EC:4.1.1.44]

3-Oxoadipate enol-lactone degradation to succinyl-CoA

pcaD 3-oxoadipate enol-lactonase [EC:3.1.1.24]

pcal Acyl CoA:acetate/3-ketoacid CoA transferase, alpha subunit [EC:2.8.3.12]

pcaJ Acyl CoA:acetate/3-ketoacid CoA transferase, beta subunit [EC:2.8.3.12]

pcaR beta-ketoadipate pathway transcriptional regulators, PcaR/PcaU/PobR family [K02624]

pcaK MFS transporter, AAHS family, 4-hydroxybenzoate transporter [KO:K08195]

pcaK MFS transporter, AAHS family, 4-hydroxybenzoate transporter [KO:K08195]

pcaF 3-oxoadipyl-CoA thiolase [EC:2.3.1.174]

\section{Homogentisate pathway and catabolism of phenylalanine and tyrosine}

L-Phenylalanine degradation

phhA phenylalanine-4-hydroxylase [EC:1.14.16.1]

Tyrosine degradation I to acetoacetate and fumarate

tyrB aromatic-amino-acid transaminase [EC:2.6.1.57]

tyrB aromatic-amino-acid transaminase [EC:2.6.1.57]

$h p p D$ 4-hydroxyphenylpyruvate dioxygenase [EC:1.13.11.27]

$h p p D$ 4-hydroxyphenylpyruvate dioxygenase [EC:1.13.11.27]

hmgA homogentisate 1,2-dioxygenase [EC:1.13.11.5]

hmgC maleylacetoacetate isomerase [EC:5.2.1.2]

hmgB fumarylacetoacetase [EC:3.7.1.2]

Tyrosine (4-Hydroxyphenylacetate/3-Hydroxyphenylacetate) degradation II to succinate

hpaC 4-hydroxyphenylacetate-3-hydroxylase small chain [EC:1.14.13.3]

hpaB 4-hydroxyphenylacetate-3-hydroxylase large chain [EC:1.14.13.3]

hpaD 3,4-dihydroxyphenylacetate 2,3-dioxygenase [EC:1.13.11.15]

hpaE 5-carboxymethyl-2-hydroxymuconic-semialdehyde dehydrogenase [EC:1.2.1.60]

hpaF 5-carboxymethyl-2-hydroxymuconate isomerase [EC:5.3.3.10]

hpaF 5-carboxymethyl-2-hydroxymuconate isomerase [EC:5.3.3.10]

$\begin{array}{llll}1630 & 3860 & 2532 & 1674 \\ 1631 & 3861 & 2531 & 1673 \\ 1632 & 3862 & 2530 & 1672 \\ 1633 & 3863 & 2529 & -\mathrm{b} \\ 1264 & 5395 & 0155 & 1250 \\ 1265 & 5396 & 0154 & 1249 \\ 1266 & 5396 & 0154 & 1249 \\ 1267 & 5397 & 0153 & 1248 \\ 2952 & 1320 & - & - \\ 2953 & 1321 & - & - \\ 2954 & 1322 & 0225 & - \\ 2955 & 1323 & 0226 & 1257 \\ 2957 & 1325 & 0227 & 1259 \\ & & & \\ 2956 & 1324 & 0226 & 1258 \\ 2949 & 1317 & 0222 & 1254 \\ 2950 & 1318 & 0223 & 1255 \\ 2946 & 1315 & 0156 & 1253 \\ 2947 & 1316 & 0231 & - \\ 2948 & 1316 & 0231 & - \\ 2951 & 1319 & 0224 & 1256\end{array}$


Table 2 Comparison of putative genes related to main pathways for central aromatic catabolism among pseudomonad PGPR (Continued)

\begin{tabular}{|c|c|c|c|c|c|}
\hline hpaG & 5-oxopent-3-ene-1,2,5-tricarboxylate decarboxylase, C-terminal subunit [EC:4.1.1.68] & 5411 & 3371 & 0817 & - \\
\hline hpaG & 5-oxopent-3-ene-1,2,5-tricarboxylate decarboxylase, N-terminal subunit [EC:4.1.1.68] & 5412 & 3370 & 0818 & - \\
\hline hpaA & 4-hydroxyphenylacetate catabolism regulatory protein [KO:K02508] & 5413 & 3369 & 0819 & - \\
\hline hpaH & 2-oxo-hept-3-ene-1,7-dioate hydratase [EC:4.2.1.-] & 5406 & 3376 & 0812 & - \\
\hline hpal & 2,4-dihydroxyhept-2-ene-1,7-dioic acid aldolase [EC:4.1.2.-] & 5405 & 3377 & 0811 & - \\
\hline hpal & 2,4-dihydroxyhept-2-ene-1,7-dioic acid aldolase [EC:4.1.2.-] & 2721 & - & - & - \\
\hline$g a b D$ & succinate-semialdehyde dehydrogenase (NADP+) [EC:1.2.1.16] & 5324 & 0185 & 0260 & 0096 \\
\hline$g a b D$ & succinate-semialdehyde dehydrogenase (NADP+) [EC:1.2.1.16] & 2687 & 0185 & - & 0740 \\
\hline \multicolumn{6}{|c|}{ Phenylethylamine degradation II to phenylacetate } \\
\hline pead & quinohemoprotein amine dehydrogenase, beta subunit [TIGR03907] & 1726 & 4117 & - & - \\
\hline peac & quinohemoprotein amine dehydrogenase, gamma subunit [pfam08992] & 1727 & 4118 & - & - \\
\hline peaA & quinohemoprotein amine dehydrogenase, alpha subunit [TIGR03908] & 1729 & 4120 & - & - \\
\hline peaE & phenylacetaldehyde dehydrogenase [EC:1.2.1.39] & 1734 & 4130 & - & - \\
\hline peaE & phenylacetaldehyde dehydrogenase [EC:1.2.1.39] & 5496 & 3217 & 0867 & - \\
\hline \multicolumn{6}{|c|}{ Phenylacetyl-CoA pathway } \\
\hline paaf & phenylacetate-CoA ligase [EC:6.2.1.30] & 0341 & 3132 & - & - \\
\hline paaD & acyl-CoA thioesterase [EC:3.1.2.-] & 0343 & 3131 & - & - \\
\hline paaG & phenylacetate-CoA oxygenase, PaaG subunit [KO:K02609] & 0340 & 3133 & - & - \\
\hline paaH & phenylacetate-CoA oxygenase, PaaH subunit [KO:K02610] & 0339 & 3134 & - & - \\
\hline paal & phenylacetate-CoA oxygenase, Paal subunit [KO:K02611] & 0338 & 3135 & - & - \\
\hline paal & phenylacetate-CoA oxygenase, PaaJ subunit [KO:K02612] & 0337 & 3136 & - & - \\
\hline paak & phenylacetate-CoA oxygenase, PaaK subunit [KO:K02613] & 0336 & 3137 & - & - \\
\hline paan & MaoC_dehydratas/NAD-dependent aldehyde dehydrogenases [KO:K02618] & 0332 & 3140 & - & - \\
\hline paaE & 3-oxoadipyl-CoA thiolase [EC:2.3.1.16] & 0342 & 1319 & 0224 & 1256 \\
\hline$p a a B$ & enoyl-CoA hydratase [EC:4.2.1.17] & 0345 & 3130 & - & - \\
\hline paaA & enoyl-CoA hydratase [EC:4.2.1.17] & 0346 & - & - & - \\
\hline paac & 3-hydroxybutyryl-CoA dehydrogenase [EC:1.1.1.157] & 0344 & - & - & - \\
\hline paaY & phenylacetic acid degradation protein PaYY [KO:K08279] & 0347 & 3129 & - & - \\
\hline paax & phenylacetic acid degradation operon negative regulatory protein PaaX [KO:K02616] & 0348 & 3128 & - & - \\
\hline
\end{tabular}

${ }^{a}$ Homologous genes were analyzed at $60 \%$ identity threshold using IMG software.

b "-" No homologs were present in the compared genome.

Antibiotic resistance assays showed that GP72 displays resistance to penicillin, spectinomycin, streptomycin, and tetracycline. Here, our genomic analyses confirmed different kinds of defenses in the four PGPR, including resistance/tolerance to heavy metals, temperature stress, osmotic stress, oxidative stress, and multiple drugs.

Many essential trace elements contain metal ions that are important components of the active sites of many enzymes. As such, they play a vital role in many biological processes, including photosynthetic and respiratory pathways. However, most heavy metals are toxic at higher concentrations. For example, copper ions can damage the cytoplasmic membrane of $E$. coli by catalyzing harmful redox reactions [84]. In many regions, agricultural soils are heavily contaminated with various heavy metals originating from chemical fertilizers and industrial processes. Consequently, certain soil bacteria have developed resistance to toxic metals, either via active efflux mechanisms to pump the toxic metals out [85], or by enzymatic detoxification to convert a toxic ion into a harmless one [86,87]. Our genomic analysis revealed many genes related to heavy metal resistance (summarized in Table 4).

The four pseudomonad PGPR studied contained at least two different copper resistance systems, which resemble those identified in the plant growth-promoting endophytic bacterium $P$. putida W619 [15]. One system is periplasmic detoxification encoded by $\operatorname{cop} A B C D G \operatorname{cop} R S$, which is wellcharacterized in the plasmid $\mathrm{pPT} 23 \mathrm{D}$ from $P$. syringae $\mathrm{pv}$. tomato strain PT23.2 [88]. This system is also widely 
Table 3 Numbers of putative genes encoding transporters in genomes of four pseudomonad PGPR

\begin{tabular}{|c|c|c|c|c|}
\hline & GP72 & Pf-5 & M18 & A1501 \\
\hline Carbohydrate transporter genes & 125 & 108 & 103 & 46 \\
\hline Major facilitator family (MFS) & 76 & 75 & 75 & 17 \\
\hline ATP binding cassette (ABC) family & 32 & 19 & 11 & 11 \\
\hline $\begin{array}{l}\text { Tripartite ATP-Independent } \\
\text { periplasmic transporter family }\end{array}$ & 5 & 5 & 10 & 14 \\
\hline Phosphotransferase system (PTS) & 6 & 6 & 4 & 3 \\
\hline Gluconate transporter GntT & 6 & 5 & 3 & 1 \\
\hline Amino acid transporter genes & 181 & 207 & 109 & 71 \\
\hline$A B C$ transporter & 137 & 156 & 70 & 55 \\
\hline Lysine exporter (LysE) family & 18 & 24 & 13 & 11 \\
\hline $\begin{array}{l}\text { Amino acid-polyamine-organocation } \\
\text { (APC) family }\end{array}$ & 16 & 21 & 21 & 5 \\
\hline $\begin{array}{l}\text { Drug/metabolite transporter (DMT) } \\
\text { family }\end{array}$ & 10 & 6 & 5 & 0 \\
\hline $\begin{array}{l}\text { Transporter genes related to } \\
\text { defense }\end{array}$ & 79 & 78 & 48 & 38 \\
\hline$A B C$ transporter & 37 & 46 & 24 & 19 \\
\hline $\begin{array}{l}\text { Resistance-nodulation-cell-division } \\
\text { (RND) family }\end{array}$ & 35 & 25 & 15 & 15 \\
\hline $\begin{array}{l}\text { Multidrug and toxic compound } \\
\text { extrusion (MATE) family }\end{array}$ & 3 & 4 & 2 & 2 \\
\hline $\begin{array}{l}\text { Small multidrug resistance } \\
\text { (SMR) family }\end{array}$ & 4 & 3 & 7 & 2 \\
\hline
\end{tabular}

distributed in other Pseudomonas species $[15,88,89]$. Another copper resistance system is the cytoplasmic detoxification system cue, which maintains a strict quota of cellular copper in other organisms [90,91]. The $\mathrm{Cu}(\mathrm{I})$-responsive transcriptional regulator CueR [91] activates expression of a copper-translocating P-type ATPase (CopA) [92], a periplasmic multicopper oxidase (CueO) [93], and a copper chaperone (CopZ) [90] under mild copper stress. CopA exports $\mathrm{Cu}(\mathrm{I})$ from the cytoplasm to the periplasm, and then $\mathrm{Cu}(\mathrm{I})$ is converted into the less toxic $\mathrm{Cu}$ (II) form by $\mathrm{CueO}$. A third copper resistance strategy in the genome of GP72 consisted of cusFABBC (MOK_00020-00016) and copRS (MOK_00012-00013). The cus operon is related to periplasmic detoxification, and is exclusively found in Gramnegative bacteria [94,95]. Therefore, the mechanism for copper resistance in P. chlororaphis is very complex, and has not been completely characterized yet. Further research is required to clarify the details of this system.

Pseudomonas spp. have arsenic-resistance genes (arsRB, ars $C H$ and $\operatorname{ars} C$ ) that are dispersed throughout the genome. The chromosomal ars operon was characterized in P. aeruginosa. A homologous ars operon was detected in some, but not all, Pseudomonas species, indicating that some other mechanisms are involved in arsenic resistance in pseudomonads [96]. Our genomic analysis indicated that the GP72 genome lacked a homologous gene encoding an arsenite- and antimonite-stimulated ATPase (ArsA). However, a previous study showed that ArsB could export arsenite ions in the absence of ArsA in E. coli [97]. Since ArsB was predicted in the genome of GP72, we can assume that this strain also shows arsenic resistance. The $c z c A B C R D$ operon encoding a cation-proton antiporter, which is responsible for cobalt, zinc, and cadmium resistances [98], was predicted in the genomes of GP72 and Pf5. Other genes found in their genomes may also be related to heavy metal resistance, such as homologs of chrA and chrB genes involved in chromate resistance [99], and homologs of genes encoding siderophores that participate in metal homeostasis in P. aeruginosa [100].

In recent years, multidrug resistance has reached alarming levels, especially in the field of medicine [101]. Such resistance mechanisms have been fully described by Alekshun and Levy [102]. Some PGPR strains contain a broad spectrum of putative multidrug resistance genes, including genes related to well-developed efflux systems [103], penicillin-binding protein-mediated resistance [104], and enzymes that degrade antibiotics (Additional file 2). Efflux systems contribute significantly to resistance to multiple antimicrobial compounds. This is a very important mechanism to enhance biological fitness [105]. Like other Pseudomonas species, GP72 contained 37 putative $\mathrm{ABC}$ transporters, which potentially participate in the uptake or efflux of toxic metabolites and other drugs. Some secondary transport system genes were also present in GP72 (Table 3); there were 35 genes encoding RND family members, three genes for MATE family members, and four genes for SMR family members. All pseudomonad PGPR contained genes encoding the efflux pumps TtgABC and TtgDEF (toluene tolerance genes). These enzymes prevent the accumulation of toluene and other related aromatics, such as phenol [106]. Genes encoding an MexEFOprN efflux pump, a member of the RND family, were also present in the genomes of GP72, Pf-5, M18, and A1501, but the order of the efflux pump genes in the genome differed among the four strains. The efflux pump operon is upregulated by MexT under nitrosative stress and chloramphenicol stress [107]. Overexpression of this system can decrease the production of several secondary metabolites such as PYO, elastase, and rhamnolipids [108]. AcrB (homologous to MOK_00261 in the GP72 genome), which also belongs to the RND family [109], plays a role in pumping out basic dyes (such as acriflavine), most antibiotics (except aminoglycosides), and detergents (such as bile salts, Triton X-100, and SDS) [110]. In conclusion, the genomic data indicated that these PGPR harbor genes that can confer resistance to multiple drugs, including penicillin, aminoglycosides, fluoroquinolones, trimethoprimsulfamethoxazole, lipid A, and acriflavine.

Bacteria that inhabit the rhizosphere of plants can use plant-derived compounds as nutrients; however, they must 
Table 4 Summary and comparison of putative genes related to metal resistance in four pseudomonad PGPR genomes

\begin{tabular}{lll}
\hline & & Homologs $^{\text {a }}$ in PGPR \\
\hline Gene & Product name & GP72 ORF Pf-5 ORF M18 ORF A1501 ORF \\
& & ID MOK_0 ID PFL_ ID PAM18_ ID PST_
\end{tabular}

\section{Copper resistance}

$\begin{array}{ll}\text { copG } & \text { predicted metal-binding protein } \\ \text { copD } & \text { putative copper export protein } \\ \text { copC } & \text { uncharacterized protein, homolog of Cu resistance protein CopC } \\ \text { copB } & \text { uncharacterized protein involved in copper resistance } \\ \text { copA } & \text { copper-resistance protein, CopA family } \\ - & \text { uncharacterized copper-binding protein } \\ \text { copR } & \text { heavy metal response regulator } \\ \text { copS } & \text { heavy metal sensor kinase[EC:2.7.13.3] } \\ \text { copC } & \text { uncharacterized protein, homolog of Cu resistance protein CopC } \\ \text { copD } & \text { putative copper export protein } \\ \text { cueO } & \text { putative multicopper oxidases } \\ \text { cueR } & \text { Cu(I)-responsive transcriptional regulator } \\ \text { copA } & \text { copper-(or silver)-translocating P-type ATPase[EC:3.6.3.4] } \\ \text { copZ } & \text { copper chaperone }\end{array}$

\begin{tabular}{|c|c|c|c|}
\hline 0288 & 2891 & 4821 & 3385 \\
\hline 0289 & $-b$ & - & - \\
\hline 0290 & - & - & - \\
\hline 0291 & 2892 & 2980 & 3381 \\
\hline 0292 & 2893 & 2979 & 3383 \\
\hline 3441 & 1966 & 2156 & - \\
\hline 3442 & 1965 & 2154 & 2712 \\
\hline 3443 & 1964 & 2153 & - \\
\hline 3597 & 2543 & - & - \\
\hline 3598 & 2542 & - & - \\
\hline 0816 & 4929 & 1176 & 3006 \\
\hline 4686 & 0709 & 4886 & 3614 \\
\hline 4687 & 0710 & 1020 & 3613 \\
\hline 4689 & 0712 & 1410 & - \\
\hline 0912 & 5050 & 3694 & - \\
\hline 0913 & 5051 & - & - \\
\hline 0016 & - & - & - \\
\hline 0017 & - & - & - \\
\hline 0018 & - & - & 2082 \\
\hline 0019 & - & - & 2083 \\
\hline 0020 & - & - & - \\
\hline 0160 & - & 2763 & 2096 \\
\hline 0161 & 2185 & 2762 & - \\
\hline 5909 & 2184 & 2761 & - \\
\hline 5910 & 2183 & 2760 & 2097 \\
\hline 5052 & 4456 & 4088 & 2824 \\
\hline 1084 & 5218 & 2519 & 3425 \\
\hline 1085 & 5219 & 2518 & - \\
\hline 1086 & 5220 & - & - \\
\hline 1087 & 5221 & 2516 & 3421 \\
\hline 1088 & 5222 & 0397 & - \\
\hline 0320 & 3149 & 4378 & - \\
\hline 42 & - & - & 2920 \\
\hline 4262 & - & - & 2921 \\
\hline
\end{tabular}

\section{Copper/silver resistance}

\begin{tabular}{|c|c|}
\hline CusR & $\begin{array}{l}\text { two-component system, OmpR family, copper resistance phosphate regulon } \\
\text { response regulator CusR }\end{array}$ \\
\hline cuss & $\begin{array}{l}\text { two-component system, OmpR family, heavy metal sensor histidine kinase CusS } \\
\text { [EC:2.7.13.3] }\end{array}$ \\
\hline CusC & heavy metal RND efflux outer membrane protein, CzcC family \\
\hline usB & heavy metal RND efflux outer membrane protein, $\mathrm{CzcC}$ family \\
\hline Cus $B$ & $\mathrm{Cu}(\mathrm{I}) / \mathrm{Ag}(\mathrm{I})$ efflux system membrane protein CusB \\
\hline CUSA & $\mathrm{Cu}(\mathrm{I}) / \mathrm{Ag}(\mathrm{I})$ efflux system membrane protein CusA \\
\hline & $\mathrm{Cu}(\mathrm{I}) / \mathrm{Ag}(\mathrm{I})$ efflux system periplasmic protein CusF \\
\hline
\end{tabular}

\section{Arsenic resistance}

$\begin{array}{ll}\operatorname{ars} R & \text { predicted transcriptional regulators } \\ \operatorname{ars} B & \text { arsenical pump membrane protein } \\ \operatorname{ars} \mathrm{C}-2 & \text { arsenate reductase } \\ \operatorname{arsH} & \text { arsenical resistance protein ArsH } \\ \operatorname{ars} \mathrm{C}-1 & \text { arsenate reductase (glutaredoxin)[EC:1.20.4.1] }\end{array}$

\section{Cobalt/zinc/cadmium resistance}

$\begin{array}{ll}C Z C A & \text { heavy metal efflux pump (cobalt-zinc-cadmium) } \\ C z C B & \text { RND family efflux transporter, MFP subunit } \\ C z C C & \text { outer membrane protein } \\ C z C R & \text { heavy metal response regulator } \\ C Z C D & \text { cation diffusion facilitator family transporter }\end{array}$

\section{Chromate resistance}

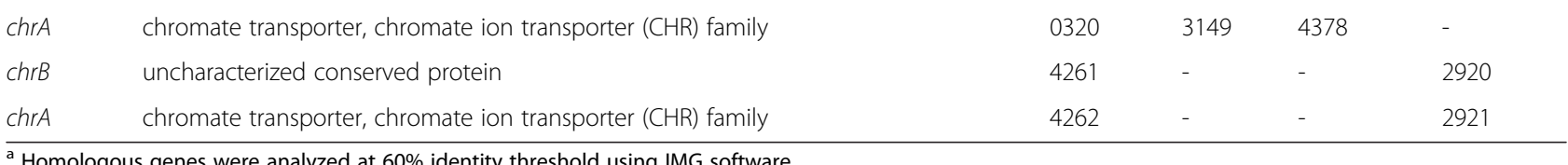

\footnotetext{
${ }^{a}$ Homologous genes were analyzed at $60 \%$ identity threshold using IMG software.
}

b " " No homologs were present in the compared genome. 
be able to tolerate damaging compounds produced by plants, such as reactive oxygen species (ROS). Several ROS are continuously produced during aerobic metabolism of plants. They participate in regulating plant cell expansion [111] and other biological processes. ROS show antimicrobial activities [112], as they can damage proteins, nucleic acids, and cell membranes. Rhizospheric bacteria produce several enzymes to resist oxidative stress [113]. Genes encoding these enzymes have already been identified in the genomes of Pf-5 and A1501 [17,18]. Putative ROS-detoxifying enzymes in GP72 included 11 peroxidases, five catalases, two superoxide dismutases, and 19 glutathione S-transferases. There was no significant difference in the numbers of these enzymes among the four PGPR (Figure 6). Genes encoding regulators of the oxidative stress response, including the two-component regulator GacS/GacA [114], SoxR, and OxyR [113,115] were present in the genomes of GP72, Pf-5, M18, and A1501. However, a homolog of SoxR in $P$. aeruginosa did not function as a key regulatory player in the bacterial oxidative stress response [116]. Exopolysaccharides such as alginate [117] and polyhydroxyalkanoates (PHAs) [118] are important for tolerance to oxidative stress under ambient pressure. For instance, PHA accumulation enhances the survival of pseudomonads under salinity stress, oxidative stress, and cold-shock $[119,120]$. Additionally, a pyrroloquinolinequinine (PQQ) synthase expressed in E. coli improves its resistance to photodynamically produced ROS [121].

Rhizosphere bacteria usually survive in a changeable environment; therefore, they have evolved several traits related to adaptation [122]. The genomes of GP72, Pf-5, M18, and A1501 contained homologs of genes related to tolerating cold-shock, including $\operatorname{csp} A C D G$, which is constitutively expressed at $37^{\circ} \mathrm{C}$ [123]. In $P$. aeruginosa cells, a temperature increase from 30 to $45^{\circ} \mathrm{C}$ enhances production of 17 proteins, including the heat-shock proteins DnaK and GroEL [124]. A chaperone system formed by DnaK, DnaJ, and GrpE proteins modulates the heat-shock response in E. coli [125] (Additional file 2). As an opportunistic pathogen, $P$. aeruginosa has evolved to survive in diverse stressful environments. A microarray analysis showed that $P$. aeruginosa synthesizes osmoprotective compounds, such as hydrophilins and osmoprotectants, to cope with osmotic stress [126,127]. Glycine betaine (GB), a major osmoprotectant for many bacteria [128], can accumulate via de novo synthesis or via absorption from the environment [126]. Mutant analyses and ${ }^{13} \mathrm{C}$ NMR studies confirmed GB catabolism in P. aeruginosa [129]. Previously, it was shown that GP72 shows strong osmotic stress tolerance [7]. The genomic analysis in this study showed that the genomes of GP72, Pf-5, and M18 contained at least one complete gene set required for conversion of $\mathrm{GB}$ to glycine; this gene set included $g b c A B, \operatorname{dgc} A B$, and soxGADB. In contrast, A1501 contained only a homolog of the bet $A B$ operon, which encodes a system for oxidation of choline to GB under osmotic stress conditions [130]. Osmoregulated periplasmic glucans are highly branched oligosaccharides found in the periplasm of Gram-negative bacteria. They are probably produced in response to periplasmic osmolality, which is controlled by the products of $m d o D$ and $m d o G$ [131]. Enteric bacteria can modulate their cytoplasmic osmolality through mobilizing $\mathrm{K}^{+}$, glutamate, and other compatible solutes, such as trehalose, proline, and GB [132]. $\mathrm{K}^{+}$first responds to osmotic upshifts via the transporters Trk and Kdp, possibly acting as a putative osmoregulatory second messenger $[126,133]$. The genes related to osmotic stress tolerance are listed in Additional file 2.

We found that resistance genes were present in the genomes of all four PGPR, although some genes showed low similarity to others. These results indicated that PGPR may undergo long-term evolution to adapt to specific ecological niches. To adapt to changeable environments, each pseudomonad PGPR strain has a complex array of regulatory networks, including sigma factors, transcriptional regulators, and a variety of two-component transcriptional regulators.

\section{Rhizosphere colonization}

A confocal laser scanning microscopy analysis showed that P. fluorescens WCS365 and P. chlororaphis PCL1391 are able to effectively colonize the tomato rhizosphere [134], and the major traits for niche competition were identified [135]. Development of new genetic approaches such as in vivo expression technology (IVET) together with "omic" technologies has provided opportunities to identify genes required for rhizosphere competence, and to elucidate the genetic mechanisms of plant-microbe interactions $[14,136]$. Pseudomonad PGPR show certain competitive

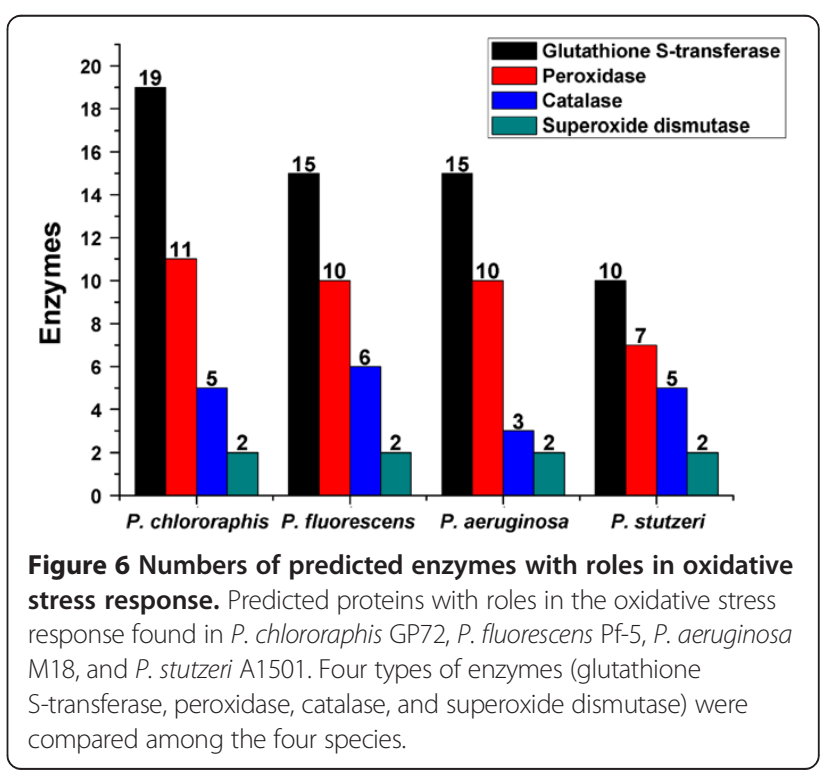


colonization traits, such as motility and the ability to attach to the root surface.

First, motility is a major trait for the competitive tomato root-tip colonization of $P$. fluorescens, based on chemotaxis $[137,138]$. We found genes related to chemotaxis and motility in the genomes of the four PGPR; GP72 contained 14 genes responsible for various aspects of chemotaxis, including genes encoding a two-component system (CheA/CheY). The activity of the histidine kinase CheA can be regulated by methyl-accepting chemoreceptor proteins (MCPs) during chemotaxis [139]. Swimming behavior can be initiated when the phosphorylated CheY binds to the flagellar switch protein, Flim [140]. In the present study, we found 28 genes encoding MCPs and 40 genes associated with flagella biosynthesis, including the $f l g$ and $f l i$ operons.

The second trait of competitive colonization is attachment to the root surface. In this study, several genes involved in attachment were predicted in the PGPR genomes (Additional file 3). The functions of some genes have been confirmed experimentally in certain Pseudomonas species, including genes associated with type IV pili and twitching motility [141], genes for biosynthesis of alginate [142], hemolysin [135,143], filamentous hemagglutinin [144], and lipopolysaccharide O-antigen [145], and genes for other enzymes or factors involved in adhesion [135]. For instance, twitching motility, a type of flagella-independent surface motility mediated by type IV pili, is a mechanism of rapid bacterial colonization [141]. As well as the common type IV pilus assembly proteins, we identified a second set of genes in P. chlororaphis GP72 that were previously reported to play roles in the biogenesis of the Flp subfamily of type IVb tight adherence (Tad) pili [146]. However, tad genes were not found in the genomes of the other three PGPR at the $60 \%$ identity threshold, when compared with the genome of GP72. Tad pili are an essential and conserved host-colonization factor in Bifidobacterium species [147]. Therefore, we can speculate that the tad genes are probably derived from organisms outside of the genus Pseudomonas. In strain P. putida KT2440, a series of rap genes (root-activated promoters) were identified during maize root colonization by IVET [148]. Some of the promoters isolated by rap fusions responsible for adhesion were present in the genomes of GP72, Pf-5, and M18, such as secB ( $\mathrm{rap}_{1-2}$ fusion) [135] and $\operatorname{algD}$ ( $\mathrm{rap}_{2-45}$ fusion) [142]. The genetic locus $a g g A$, which is involved in agglutination and adherence [149], was also predicted in the genomes of GP72 and Pf-5. Espinosa-Urgel et al. [143] characterized several mus (mutants unattached to seeds) loci in P. putida, and confirmed that mutants of these loci show impaired attachment to corn seeds. The genome of GP72 contained four mus loci: mus-13, mus-21, mus-24, and mus-27, with possible functions as a carbon starvation protein, transporter, calcium-binding protein, and hemolysin, respectively. Genes involved in competitive rhizosphere colonization have been well studied in P. fluorescens. These include $x e r C$, which encodes a site-specific recombinase. xerC is a homolog of sss in P. chlororaphis PCL1391; sss plays a role in phase variation caused by DNA rearrangements $[3,150]$. The nuo operon encodes subunits of NADH: ubiquinone oxidoreductase, which is related to ATP-dependent rotation of flagella [145]. Some of the genes isolated by IVET and identified to play roles in plant-microbe interactions $[14,151]$ were present in the genomes of GP72, Pf-5, M18, and A1501 when compared with the genome of $P$. fluorescens SBW25 (data not shown). However, it remains to be confirmed whether these genes specifically contribute to rhizosphere competence.

GP72, Pf-5, and A1501 lacked virulence factors found in plant pathogens, such as the type III secretion system, phytotoxins, and exoenzymes associated with cell wall degradation. Homologs of genes encoding phytotoxins produced by $P$. syringae (coronatine, syringomycin, syringopeptin, tabtoxin, and phaseolotoxin) [152] were also absent from the genomes of GP72, Pf-5, M18, and A1501. Their genomes did not contain genes related to the biosyntheses of cellulases, pectinases, or pectin lyases, which play roles in the degradation of cell wall components. Therefore, the lack of these genes can result in efficient rhizosphere colonization and improvement of plant growth.

\section{Biocontrol activities}

Biocontrol activities are important mechanisms by which PGPR suppress plant pathogens. The main biocontrol strategy is the production of a spectrum of antibiotics [2]. The antibiotics produced by the biocontrol agents GP72, Pf-5, and M18 are listed in Table 5. Phenazines are versatile secondary metabolites produced by $P$. fluorescens, P. chlororaphis, and Pseudomonas aureofaciens [153]. These compounds play critical roles in the biological control activities of Pseudomonas spp. [5]. Previous studies showed that GP72 can completely suppress various phytopathogens, mainly because of the production of PCA and 2-OH-PHZ. Clusters of phenazine-compound biosynthetic genes were present in the genomes of both GP72 and M18, but the genes differed between the two species. The GP72 genome contained $p h z O$, encoding an aromatic monooxygenase [154] that converts PCA to 2-OH-PHZ, whereas M18 contained two $p h z$ gene clusters and one set of modified $p h z M S$ genes. $p h z M$ and $p h z S$ encode a putative S-adenosylmethionine-dependent $\mathrm{N}$-methyltransferase and a putative flavin-dependent hydroxylase, respectively. They participate in the conversion of PCA to PYO in $P$. aeruginosa. PYO is a virulence factor to cystic fibrosis patients infected by pathogenic pseudomonads [155]. However, M18 does not produce detectable levels of PYO at $28^{\circ} \mathrm{C}$, mainly because of the temperature-dependent expression of $p h z M$ and its regulatory genes lasI and ptsP. The biocontrol activity of M18 is, therefore, not attributed 
to PYO but to PCA [33], and it shows lower pathogenicity than other closely related strains. Previous studies showed that some plant pathogens are more strongly inhibited by 2-OH-PHZ than by PCA [154]. Another important antibiotic is Plt, which is produced by both Pf- 5 and M18. Strains with the ability to produce the insect toxin 'Fit' $(P$. fluorescens insecticidal toxin) [156] show potent insecticidal activity [157]. The fit $\bar{D}$ gene encoding the cytotoxin in GP72 showed $84 \%$ identity to that in Pf- 5 . The amino acid sequence of Fit shared $77 \%$ amino acid identity with the insect toxin Mcf (makes caterpillars floppy) produced by the entomopathogen Photorhabdus luminescens [157].

Fluorescent pseudomonads can produce pyoverdin (Pvd), a fluorescent siderophore, and chelate Fe(III) efficiently under low-iron conditions to improve their biocontrol activity [158,159]. The fluorescent pseudomonads GP72, Pf-5, and M18 contained the complete Pvd biosynthetic gene cluster. In addition, Pf- 5 and M18 contained genes encoding another siderophore, Pch, which has antifungal activity [160]. GP72 lacked these genes, but it contained putative genes for synthesis of achromobactin (Acr), a temperature-regulated secondary siderophore. The related biosynthetic gene clusters in GP72 included acsFDECBA, $y h c A$, and $a c r A B C D$, which are responsible for the biosynthesis of Acr, permease, and a specific outer membrane receptor, respectively [161,162]. Siderophores can bind metals other than iron [163] and, therefore, can play roles in sequestering toxic metals including aluminum, cobalt, copper, and lead [100]. GP72 contained a locus (MOK_02694) encoding a nickel-uptake substrate-specific transmembrane protein, adjacent to the acr operon. Acr in GP72 may be involved in metal transport, signaling pathways, or antimicrobial activities. The comparative genomic analysis indicated that there was no homology of the acr operon between Pf- 5 and M18. As well as producing their own siderophores, Pseudomonas can also use siderophores produced by other microorganisms. For example, A1501 may obtain iron via heterologous siderophores, since it lacks pathways for siderophore biosynthesis [18]. Genes involved in the uptake of soluble $\mathrm{Fe}(\mathrm{III})$ complexes, that is, those encoding putative outer membrane receptors, were present in the genomes of the four pseudomonads: 31 genes in GP72, 45 in Pf-5, 36 in M18, and 24 in A1501. The variable iron acquisition systems among Pseudomonas reflect their large capacity for niche colonization, providing insights into how their biocontrol abilities can be improved. Therefore, the availability of complete genome sequences provides an excellent opportunity to explore the diversity and evolution of biosynthetic pathways in different species/strains $[153,164]$.

\section{Direct plant-growth promotion}

Rhizobacteria can directly promote plant growth, and some strains have been developed as 'biofertilizers'. The mechanisms underlying plant-growth promotion include nitrogen fixation, increased nutrient availability, production of phytohormones, and so on [165]. The biofertilizers Azotobacter [12] and P. stutzeri [18], both of which belong to the Pseudomonadaceae, are able to fix nitrogen. The genome of A1501 contains a cluster of 59 genes specific to nitrogen fixation, and the nif operon shows a high degree of similarity to that in the genome of Azotobacter vinelandii. Therefore, we compared A1501 with GP72, Pf-5, and M18 at a threshold of $30 \%$ identity to screen for putative genes related to nitrogen fixation. The analyses revealed 13,13 , and 14 homologous genes in GP72, Pf- 5 , and M18, respectively (Additional file 4); however, these three strains lacked the nitrogenase complex-encoding genes nifDK $[166,167]$. We conducted a similar screen for denitrification genes; of 45 genes in A1501, 7 homologs were found in the genome of Pf-5, and 21 in the genome of GP72. We can speculate that the low identities may be because of the relatively distant evolutionary relationship, as shown in the phylogenetic analysis (Figure 4). GP72 and M18 contained several genes involved in denitrification: narL and narX, which encode a two-component regulatory system; narGHJI, which encodes respiratory nitrate reductase [168]; and nor genes, which are involved in nitric oxide metabolism. Previous studies reported that $P$. fluorescens and $P$. chlororaphis produce $\mathrm{N}_{2} \mathrm{O}$ as the only detectable gaseous product of denitrification [169], while P. stutzeri emits only $\mathrm{N}_{2}$, and $P$. aeruginosa produces both $\mathrm{N}_{2}$ and $\mathrm{N}_{2} \mathrm{O}$ [170]. Thus, the denitrification process can accommodate large quantities of anthropogenic nutrients, converting nitrate into nitrogen. This could decrease nitrate accumulation and counteract eutrophication in the environment [171].

Limited quantities of soluble phosphate can restrict plant growth. The genomes of GP72, Pf-5, M18, and A1501 contained several genes encoding nonspecific phosphatases, inositol phosphate phosphatases, and C-P

\begin{tabular}{|c|c|c|c|}
\hline & GP72 & Pf-5 & M18 \\
\hline Phenazine & PCA, 2-OH-PCA & $-{ }^{a}$ & PCA, PYO ${ }^{b}$ \\
\hline Pyoluteorin (PIt) & - & Plt & Plt \\
\hline Pyrrolnitrin (Prn) & Prn & Prn & - \\
\hline 2,4-diacetylphloroglucinol (DAPG) & - & DAPG & - \\
\hline Hydrogen cyanide (HCN) & $\mathrm{HCN}$ & $\mathrm{HCN}$ & $\mathrm{HCN}$ \\
\hline$\underline{P}$. fluorescens insecticidal toxin (Fit) & Fit & Mcf & - \\
\hline Pyoverdine (Pvd) & Pvd & Pvd & Pvd \\
\hline Pyochelin (Pch) & - & Pch & Pch \\
\hline Achromobactin (Acr) & Acr & - & - \\
\hline
\end{tabular}

a "_" Secondary metabolite is absent from that strain, based on previous studies and genomic sequence information.

${ }^{\mathrm{b}} \mathrm{M} 18$ did not produce detectable levels of PYO at $28^{\circ} \mathrm{C}$ [33]. 
lyases. These enzymes catalyze the conversion of insoluble phosphorus into plant-available forms, thereby facilitating plant growth [172]. In addition, many PGPR can produce phytohormones to stimulate plant growth. GP72 can synthesize IAA [7] via a tryptophan-dependent pathway [173], since it contained genes encoding tryptophan-2 -monooxygenase (iaaM, MOK_03651/04103/05943) and indoleacetamide hydrolase (iaaH, MOK_00889/01660/ 02975). A1501 lacks the putative IAA synthesis pathway [18]. The genomes of GP72, Pf-5, M18, and A1501 contained putative 1-aminocyclopropane-1-carboxylate (ACC) deaminases. This enzyme can counteract the ethylene response in plants by degrading the ethylene precursor ACC. In other Pseudomonas strains, ACC deaminases promote root elongation and suppress plant diseases [174]. Biosynthetic genes for PQQ, a plant-growth promotion factor, are clustered in the conserved pqqABCDEF operon [175]. This operon was present in the genomes of Pf-5, M18, and A1501. GP72 lacked pqqA, but the enzyme encoded by $p q q A$ is not required for biosynthesis of PQQ in Methylobacterium [176].

\section{Conclusions}

We analyzed plant growth-promoting traits by a comparative genomics analysis of four representative pseudomonad PGPR strains. The genes that were conserved among the different Pseudomonas species have provided clues to the common characteristics of pseudomonad PGPR, such as rhizosphere competence traits (nutrient catabolism and transport, resistance to various environmental stresses, and rhizosphere colonization). The strain-specific genes differentiated each strain on the basis of its lifestyle, specific ecological adaptations, and physiological role in the rhizosphere. The recently reported genome of $P$. chlororaphis, together with other sequenced strains of different species of pseudomonad PGPR, provides insights into the genetic basis of diversity and adaptation to specific environmental niches. Comparative genomic analyses, combined with certain IVET-based analyses, can reveal many genetic factors related to plant growth promotion. First, the strong adaptability of PGPR to their environment is related to putative genes involved in catabolism and transport of plant-derived compounds and resistance to various environmental stresses (heavy metals, ROS, cold-, heat-, or osmotic-shock, and multiple drugs). These genes were very common in the genomes of PGPR, especially those of $P$. chlororaphis and $P$. fluorescens, and provide the foundation for rhizosphere fitness. Second, we compared genes involved in rhizosphere colonization. Some related genes showed low similarity between $P$. chlororaphis GP72 and the other three strains, including biosynthetic genes for the O-antigen and type IV pilus assembly. Hence, GP72 may have stronger rhizosphere competence than the other three strains. Third, we analyzed genes related to biocontrol activities, namely those encoding production of antifungal metabolites such as PCA and Plt. The genomic information indicated that the secondary metabolites differ markedly among the four PGPR. For example, GP72 contained putative gene clusters for biosynthesis of the siderophore Acr, whereas the other strains contained gene clusters for biosynthesis of different siderophores. Some rhizobacteria cannot produce antifungal compounds, but promote plant growth in the absence of pathogens. One such strain was P. stutzeri A1501, which fixes nitrogen. Therefore, the metabolic pathways, transporters, and regulators related to cell metabolism provide directions to improve plant growth-promoting activities. Genetic modification may accelerate the commercialization of PGPR as biocontrol agents, which could further contribute to sustainable development of agriculture.

\section{Methods}

Medium and growth conditions for P. chlororaphis GP72 P. chlororaphis GP72 (deposited in China General Microbiological Culture Collection Center; collection number 1748), isolated from green pepper rhizosphere in eastern China, was incubated at $28^{\circ} \mathrm{C}$ in King's medium B [177].

\section{Genome sequencing and annotation}

The genome of P. chlororaphis GP72 was sequenced using the Illumina GAIIx platform and assembled using VELVET 1.1.07. The genome of GP72 was automatically annotated using the RAST server [178], and proceeded with manual curation and comparative analysis using the IMG/ER system (https://img.jgi.doe.gov/cgi-bin/er/main.cgi) [179]. The genome sequence is available at the IMG database [39]. Information of COGs [40], combined with that from the Conserved Domain Database, was also used in the comparisons. The metabolic pathways were examined using KAAS (KEGG Automatic Annotation Server) [180] and the MetaCyc database [181].

\section{Nucleotide sequence accession number}

This whole genome shotgun project has been deposited in DDBJ/EMBL/GenBank under the accession number AHAY00000000.

\section{Genome comparisons}

The genome sequence of GP72 was aligned against sequences of other Pseudomonas genomes from NCBI's Entrez database and the IMG database. Pair-wise alignments were performed using WebACT (http://www. webact.org/WebACT/home) [41]. BLAST atlases [42] were generated using the CBS DTU online tool, GeneWiz browser 0.94 server (http://www.cbs.dtu.dk/services/ gwBrowser/). Strain-specific and conserved genes were identified using the mGenomeSubtractor web server 
(http://bioinfo-mml.sjtu.edu.cn/mGS/) [43]. The conserved CDSs were identified using a homology $(\mathrm{H})$ value cut-off of 0.42 at E-value $<10^{-5}$. Comparative genomic analyses of GP72, Pf-5, M18, and A1501 were conducted using the tool set available at the IMG website; genes homologous to those in GP72 were computed with an E-value $<10^{-2}$ and at $60 \%$ identity; BLAST comparisons between PGPR and P. stutzeri A1501 were screened at the $30 \%$ identity threshold.

\section{Phylogenetic analysis}

The phylogenetic relationships among completely sequenced Pseudomonas were determined by a multilocus sequence analysis using a concatenated data set of $\operatorname{gyr} B$ and $r p o D$ genes. Multiple-sequence alignments were carried out with Clustal W (http://www.genome.jp/tools/clustalw/) [182]. Evolutionary distances were calculated using the neighbor-joining method [183] with 1000 bootstrap replicates, using Phylip 3.67 software (http://evolution.genetics. washington.edu/phylip.html). The phylogenetic tree was generated using interactive tree of life (iTOL) software [184].

\section{Additional files}

Additional file 1: Comparison of putative genes related to peripheral pathways for aromatic catabolism among pseudomonad PGPR.

Additional file 2: Putative genes involved in tolerance to antibiotics, osmotic-, and temperature-shock in the pseudomonad PGPR genomes.

Additional file 3: Comparison of putative genes related to attachment to plant rhizosphere among pseudomonad PGPR.

Additional file 4: Comparison of putative genes involved in nitrogen fixation and denitrification process among pseudomonad PGPR.

\footnotetext{
Abbreviations

PGPR: Plant growth-promoting rhizobacteria; COG: Clusters of Orthologous Groups; Plt: Pyoluteorin; Prn: Pyrrolnitrin; PCA: Phenazine-1-carboxylic acid; 2-OH-PHZ: 2-Hydroxyphenazine; HCN: Hydrogen cyanide; IAA: Indole-3-acetic acid; PYO: Pyocyanin; Pvd: Pyoverdin; Pch: Pyochelin; ACT: Artemis Comparison Tool; DO: Dioxygenase; Tyr: Tyrosine; HPP: 4-Hydroxyphenylpyruvate; HPC: Homoprotocatechuate (3,4-Dihydroxyphenylacetate); HPCD: 3,4-Dihydroxyphenylacetate 2,3-dioxygenases; ROS: Reactive oxygen species; PHA: Polyhydroxyalkanoate; PQQ: Pyrrolquinoline quinine; GB: Glycine betaine; IVET: in vivo expression technology; $A B C$ transporter: ATP binding cassette transporter; MFS: Major facilitator superfamily; TRAP-T: Tripartite

ATP-independent periplasmic transporter; PTS: Phosphotransferase system; GntT: Guconate transporter; LysE family: Lysine exporter family; RhtB family: Resistance to homoserine/threonine family; APC family: Amino acidpolyamine-organocation family; DMT family: Drug/metabolite transporter family; RND family: Resistance-nodulation-cell-division family; MATE family: Multidrug and toxic compound extrusion family; SMR family: Small multidrug resistance family; Fit: P. fluorescens insecticidal toxin; Mcf: Makes caterpillars floppy; Acr: Achromobactin; ACC: 1-Aminocyclopropane-1-carboxylate; iTOL: Interactive tree of life.
}

\section{Competing interests}

The authors declare that they have no competing interests.

\section{Authors' contributions}

XHZ, XMS, HBH, and HSP conceived, coordinated, and designed the study. WW, XHZ and XMS were responsible for sequencing, finishing, and annotating. XMS, XHZ, and HSP performed experiments and data analyses. $\mathrm{XHZ}, \mathrm{XMS}$, and $\mathrm{HBH}$ drafted the manuscript. All authors read and approved the final manuscript.

\section{Acknowledgements}

We are grateful to many people who have extended their support to us during this project. First, we thank Dr. Huajun Zheng and his colleagues for genome sequencing performed at the Chinese National Human Genome Center, Shanghai. We thank Dr. Hongyu Ou, Shanghai Jiao Tong University, for assistance with annotation. We thank Dr. Jia Xu for advice on the manuscript. We also thank Prof. Yuquan Xu for assistance with research on $P$. aeruginosa M18. This work was supported by the National Key Basic Research Program of China (No. 2009CB118906 and No. 2012CB721005), the National Natural Science Foundation of China (No. 31270084), and the National High Technology Research and Development Program of China (No. 2012AA022107).

Received: 16 March 2013 Accepted: 16 April 2013

Published: 22 April 2013

\section{References}

1. Clarke PH: The metabolic versatility of pseudomonads. Antonie Van Leeuwenhoek 1982, 48(2):105-130

2. Haas D, Defago G: Biological control of soil-borne pathogens by fluorescent pseudomonads. Nat Rev Microbiol 2005, 3(4):307-319.

3. Chin AWTF, Bloemberg GV, Mulders IH, Dekkers LC, Lugtenberg BJ: Root colonization by phenazine-1-carboxamide-producing bacterium Pseudomonas chlororaphis PCL1391 is essential for biocontrol of tomato foot and root rot. Mol Plant Microbe Interact 2000, 13(12):1340-1345.

4. Raaijmakers JM, Bonsall RF, Weller DM: Effect of population density of Pseudomonas fluorescens on production of 2,4-diacetylphloroglucinol in the rhizosphere of wheat. Phytopathology 1999, 89(6):470-475.

5. Thomashow LS, Weller DM: Role of a phenazine antibiotic from Pseudomonas fluorescens in biological control of Gaeumannomyces graminis var. tritici. J Bacterio/ 1988, 170(8):3499-3508.

6. Huang $X$, Zhang $X, X u Y$ : PltR expression modulated by the global regulators GacA, RsmA, Lasl and Rhll in Pseudomonas sp. M18. Res Microbiol 2008, 159(2):128-136.

7. Liu $H$, He $Y$, Jiang $H$, Peng $H$, Huang $X$, Zhang $X$, Thomashow LS, Xu Y: Characterization of a phenazine-producing strain Pseudomonas chlororaphis GP72 with broad-spectrum antifungal activity from green pepper rhizosphere. Curr Microbiol 2007, 54(4):302-306.

8. Howell CR, Stipanovic RD: Suppression of Pythium ultimum-induced damping-off of cotton seedlings by Pseudomonas fluorescens and its antibiotic, pyoluteorin. Phytopathology 1980, 70:712-715.

9. Nowak-Thompson B, Chaney N, Wing JS, Gould SJ, Loper JE: Characterization of the pyoluteorin biosynthetic gene cluster of Pseudomonas fluorescens Pf-5. J Bacteriol 1999, 181(7):2166-2174.

10. Hammer PE, Hill DS, Lam ST, Van Pee KH, Ligon JM: Four genes from Pseudomonas fluorescens that encode the biosynthesis of pyrrolnitrin. Appl Environ Microbiol 1997, 63(6):2147-2154

11. Laville J, Blumer C, Von Schroetter C, Gaia V, Defago G, Keel C, Haas D: Characterization of the $h c n A B C$ gene cluster encoding hydrogen cyanide synthase and anaerobic regulation by ANR in the strictly aerobic biocontrol agent Pseudomonas fluorescens CHAO. J Bacteriol 1998, 180(12):3187-3196.

12. Okon Y, Bloemberg GV, Lugtenberg BJJ: Biotechnology of biofertilization and phytostimulation. In Agricultural Biotechnology. Edited by Altman A. New York: Marcel Dekker; 1998:327-349.

13. Rodríguez-Palenzuela P, Matas IM, Murillo J, López-Solanilla E, Bardaji L, Pérez-Martínez I, Rodríguez-Moskera ME, Penyalver R, López MM, Quesada JM, Biehl BS, Perna NT, Glasner JD, Cabot EL, Neeno-Eckwall E, Ramos C: Annotation and overview of the Pseudomonas savastanoi pv. savastanoi NCPPB 3335 draft genome reveals the virulence gene complement of a tumour-inducing pathogen of woody hosts. Environ Microbiol 2010, 12(6):1604-1620.

14. Silby MW, Cerdeño-Tárraga AM, Vernikos GS, Giddens SR, Jackson RW, Preston GM, Zhang X, Moon CD, Gehrig SM, Godfrey SAC, Knight CG, Malone JG, Robinson Z, Spiers AJ, Harris S, Challis GL, Yaxley AM, Harris D, 
Seeger K, Murphy L, Rutter S, Squares R, Quail MA, Saunders E, Mavromatis K, Brettin TS, Bentley SD, Hothersall J, Stephens E, Thomas CM, et al: Genomic and genetic analyses of diversity and plant interactions of Pseudomonas fluorescens. Genome Biol 2009, 10(5):R51.

15. Wu X, Monchy S, Taghavi S, Zhu W, Ramos J, van der Lelie D: Comparative genomics and functional analysis of niche-specific adaptation in Pseudomonas putida. FEMS Microbiol Rev 2011, 35(2):299-323.

16. Collins FS, Green ED, Guttmacher AE, Guyer MS: A vision for the future of genomics research. Nature 2003, 422(6934):835-847.

17. Paulsen IT, Press CM, Ravel J, Kobayashi DY, Myers GSA, Mavrodi DV, DeBoy RT, Seshadri R, Ren Q, Madupu R, Dodson RJ, Durkin AS, Brinkac LM, Daugherty SC, Sullivan SA, Rosovitz MJ, Gwinn ML, Zhou L, Schneider DJ, Cartinhour SW, Nelson WC, Weidman J, Watkins K, Tran K, Khouri H, Pierson EA, Pierson LS 3rd, Thomashow LS, Loper JE: Complete genome sequence of the plant commensal Pseudomonas fluorescens Pf-5. Nat Biotechnol 2005, 23(7):873-878

18. Yan Y, Yang J, Dou Y, Chen M, Ping S, Peng J, Lu W, Zhang W, Yao Z, Li H, Liu W, He S, Geng L, Zhang X, Yang F, Yu H, Zhan Y, Li D, Lin Z, Wang Y, Elmerich C, Lin M, Jin Q: Nitrogen fixation island and rhizosphere competence traits in the genome of root-associated Pseudomonas stutzeri A1501. Proc Natl Acad Sci U S A 2008, 105(21):7564-7569.

19. Nelson KE, Weinel C, Paulsen IT, Dodson RJ, Hilbert H, Martins dos Santos VAP, Fouts DE, Gill SR, Pop M, Holmes M, Brinkac L, Beanan M, DeBoy RT, Daugherty S, Kolonay J, Madupu R, Nelson W, White O, Peterson J, Khouri H, Hance I, Chris Lee P, Holtzapple E, Scanlan D, Tran K, Moazzez A, Utterback T, Rizzo M, Lee K, Kosack D, et al: Complete genome sequence and comparative analysis of the metabolically versatile Pseudomonas putida KT2440. Environ Microbiol 2002, 4(12):799-808.

20. Yu H, Tang H, Wang L, Yao Y, Wu G, Xu P: Complete genome sequence of the nicotine-degrading Pseudomonas putida strain S16. J Bacteriol 2011, 193(19):5541-5542

21. Stover CK, Pham XQ, Erwin AL, Mizoguchi SD, Warrener P, Hickey MJ, Brinkman FS, Hufnagle WO, Kowalik DJ, Lagrou M, Garber RL, Goltry L, Tolentino E, Westbrock-Wadman S, Yuan Y, Brody LL, Coulter SN, Folger KR, Kas A, Larbig K, Lim R, Smith K, Spencer D, Wong GK, Wu Z, Paulsen IT, Reizer J, Saier MH, Hancock RE, Lory S, et al: Complete genome sequence of Pseudomonas aeruginosa PAO1, an opportunistic pathogen. Nature 2000, 406(6799):959-964

22. Wu D, Ye J, Ou H, Wei $X$, Huang $X$, He $Y, X u Y$ : Genomic analysis and temperature-dependent transcriptome profiles of the rhizosphere originating strain Pseudomonas aeruginosa M18. BMC Genomics 2011, 12(1):438.

23. Buell CR, Joardar V, Lindeberg M, Selengut J, Paulsen IT, Gwinn ML, Dodson RJ, Deboy RT, Durkin AS, Kolonay JF, Madupu R, Daugherty S, Brinkac L, Beanan MJ, Haft DH, Nelson WC, Davidsen T, Zafar N, Zhou L, Liu J, Yuan Q, Khouri H, Fedorova N, Tran B, Russell D, Berry K, Utterback T, Van Aken SE, Feldblyum TV, D'Ascenzo M, et al: The complete genome sequence of the Arabidopsis and tomato pathogen Pseudomonas syringae pv. tomato DC3000. Proc Natl Acad Sci U S A 2003, 100(18):10181-10186.

24. Vodovar N, Vallenet D, Cruveiller S, Rouy Z, Barbe V, Acosta C, Cattolico L, Jubin C, Lajus A, Segurens B, Vacherie B, Wincker P, Weissenbach J, Lemaitre B, Medigue C, Boccard F: Complete genome sequence of the entomopathogenic and metabolically versatile soil bacterium Pseudomonas entomophila. Nat Biotechnol 2006, 24(6):673-679.

25. Liu H, Yan A, Zhang $X$, Xu Y: Phenazine-1-carboxylic acid biosynthesis in Pseudomonas chlororaphis GP72 is positively regulated by the sigma factor RpoN. World J Microbiol Biotechnol 2008, 24(9):1961-1966.

26. Maddula VSRK, Pierson EA, Pierson LS 3rd: Altering the ratio of phenazines in Pseudomonas chlororaphis (aureofaciens) strain 30-84: effects on biofilm formation and pathogen inhibition. J Bacterio/ 2008, 190(8):2759-2766.

27. Spencer M, Ryu CM, Yang KY, Kim YC, Kloepper JW, Anderson AJ: Induced defence in tobacco by Pseudomonas chlororaphis strain 06 involves at least the ethylene pathway. Physiol Molec Plant Pathol 2003, 63(1):27-34.

28. Shen X, Chen M, Hu H, Wang W, Peng H, Xu P, Zhang X: Genome sequence of Pseudomonas chlororaphis GP72, a root-colonizing biocontrol strain. J Bacteriol 2012, 194(5):1269-1270.

29. Liu $H$, Dong D, Peng $H$, Zhang $X, X u Y$ : Genetic diversity of phenazineand pyoluteorin-producing pseudomonads isolated from green pepper rhizosphere. Arch Microbiol 2006, 185(2):91-98.

30. Huang $L$, Chen $M$, Wang $W, H u H$, Peng $H, X u Y$, Zhang $X$ : Enhanced production of 2-hydroxyphenazine in Pseudomonas chlororaphis GP72. Eur J Appl Microbiol Biotech 2010, 89(1):169-177.
31. Howell C, Stipanovic R: Control of Rhizoctonia solani on cotton seedlings with Pseudomonas fluorescens and with an antibiotic produced by the bacterium. Phytopathology 1979, 69(5):480-482.

32. Ge $Y$, Huang $X$, Wang $S$, Zhang $X, X u Y$ : Phenazine-1-carboxylic acid is negatively regulated and pyoluteorin positively regulated by gacA in Pseudomonas sp. M18. FEMS Microbiol Lett 2004, 237(1):41-47.

33. Huang J, Xu Y, Zhang H, Li Y, Huang X, Ren B, Zhang X: Temperaturedependent expression of phzM and its regulatory genes lasl and pts $P$ in rhizosphere isolate Pseudomonas sp. strain M18. Appl Environ Microbiol 2009, 75(20):6568-6580.

34. Mavrodi DV, Bonsall RF, Delaney SM, Soule MJ, Phillips G, Thomashow LS: Functional analysis of genes for biosynthesis of pyocyanin and phenazine-1-carboxamide from Pseudomonas aeruginosa PAO1. J Bacteriol 2001, 183(21):6454-6465.

35. Gibson J, Sood A, Hogan DA: Pseudomonas aeruginosa-Candida albicans interactions: localization and fungal toxicity of a phenazine derivative. Appl Environ Microbiol 2009, 75(2):504-513.

36. Qiu Y, Mo X, You C, Wang D: Investigation of dinitrogen fixation bacteria isolated from rice rhizosphere. Chinese Sc bull (kexuetongbao) 1981, 26(26):383-384.

37. Vermeiren $H$, Willems A, Schoofs $G$, de Mot R, Keijers V, Hai W, Vanderleyden $\mathrm{J}$ : The rice inoculant strain Alcaligenes faecalis A15 is a nitrogen-fixing Pseudomonas stutzeri. Syst Appl Microbiol 1999, 22(2):215-224.

38. Li D, Yan Y, Ping S, Chen M, Zhang W, Li L, Lin W, Geng L, Liu W, Lu W, Lin $M$ : Genome-wide investigation and functional characterization of the beta-ketoadipate pathway in the nitrogen-fixing and root-associated bacterium Pseudomonas stutzeri A1501. BMC Microbiol 2010, 10(1):36.

39. Markowitz VM, Korzeniewski F, Palaniappan K, Szeto E, Werner G, Padki A Zhao X, Dubchak I, Hugenholtz P, Anderson I, Lykidis A, Mavromatis K, Ivanova N, Kyrpides NC: The integrated microbial genomes (IMG) system. Nucleic Acids Res 2006, 34(Database issue):344-348.

40. Tatusov RL, Natale DA, Garkavtsev IV, Tatusova TA, Shankavaram UT, Rao BS, Kiryutin B, Galperin MY, Fedorova ND, Koonin EV: The COG database: new developments in phylogenetic classification of proteins from complete genomes. Nucleic Acids Res 2001, 29(1):22-28.

41. Carver TJ, Rutherford KM, Berriman M, Rajandream MA, Barrell BG, Parkhill J: ACT: the Artemis Comparison Tool. Bioinformatics 2005, 21(16):3422-3423.

42. Hallin PF, Binnewies TT, Ussery DW: The genome BLASTatlas - a GeneWiz extension for visualization of whole-genome homology. Mol Biosyst 2008, 4(5):363-371.

43. Shao Y, He X, Harrison EM, Tai C, Ou HY, Rajakumar K, Deng Z mGenomeSubtractor: a web-based tool for parallel in silico subtractive hybridization analysis of multiple bacterial genomes. Nucleic Acids Res 2010, 38(Web Server issue):194-200

44. Lessie TG, Phibbs PV Jr: Alternative pathways of carbohydrate utilization in pseudomonads. Annu Rev Microbiol 1984, 38:359-388.

45. Jones-Mortimer MC, Kornberg HL: Genetical analysis of fructose utilization by Escherichia coli. Proc R Soc Lond B Biol Sci 1974, 187(1087):121-131.

46. Rovira AD: Plant root exudates. Bot Rev 1969, 35:35-57.

47. Bais HP, Weir TL, Perry LG, Gilroy S, Vivanco JM: The role of root exudates in rhizosphere interactions with plants and other organisms. Annu Rev Plant Biol 2006, 57:233-266

48. Gibson DT, Parales RE: Aromatic hydrocarbon dioxygenases in environmental biotechnology. Curr Opin Biotechnol 2000, 11(3):236-243.

49. Gao J, Ellis LB, Wackett LP: The University of Minnesota biocatalysis/ biodegradation database: improving public access. Nucleic Acids Res 2010, 38(Database issue):488-491.

50. Dagley S: Catabolism of aromatic compounds by micro-organisms. Adv Microb Physiol 1971, 6:1-46.

51. Jimenez Jl, Minambres B, Garcia JL, Diaz E: Genomic analysis of the aromatic catabolic pathways from Pseudomonas putida KT2440. Environ Microbiol 2002, 4(12):824-841.

52. Harwood CS, Parales RE: The beta-ketoadipate pathway and the biology of self-identity. Annu Rev Microbiol 1996, 50:553-590.

53. Kurnasov O, Jablonski L, Polanuyer B, Dorrestein P, Begley T, Osterman A: Aerobic tryptophan degradation pathway in bacteria: novel kynurenine formamidase. FEMS Microbiol Lett 2003, 227(2):219-227.

54. Neidle E, Hartnett C, Ornston L, Bairoch A, Rekik M, Harayama S: Nucleotide sequences of the Acinetobacter calcoaceticus ben $A B C$ genes for benzoate 1, 2-dioxygenase reveal evolutionary relationships among multicomponent oxygenases. J Bacteriol 1991, 173(17):5385-5395. 
55. Balashova NV, Stolz A, Knackmuss HJ, Kosheleva IA, Naumov AV, Boronin AM: Purification and characterization of a salicylate hydroxylase involved in 1-hydroxy-2-naphthoic acid hydroxylation from the naphthalene and phenanthrene-degrading bacterial strain Pseudomonas putida BS202-P1. Biodegradation 2001, 12(3):179-188.

56. Powlowski J, Sahlman L, Shingler V: Purification and properties of the physically associated meta-cleavage pathway enzymes 4-hydroxy-2ketovalerate aldolase and aldehyde dehydrogenase (acylating) from Pseudomonas sp. strain CF600. J Bacteriol 1993, 175(2):377-385.

57. Lee SJ, Ko JH, Kang HY, Lee Y: Coupled expression of MhpE aldolase and MhpF dehydrogenase in Escherichia coli. Biochem Biophys Res Commun 2006, 346(3):1009-1015.

58. Harwood CS, Nichols NN, Kim MK, Ditty JL, Parales RE: Identification of the pcaRKF gene cluster from Pseudomonas putida: involvement in chemotaxis, biodegradation, and transport of 4-hydroxybenzoate. J Bacteriol 1994, 176(21):6479-6488.

59. Priefert H, Rabenhorst J, Steinbuchel A: Molecular characterization of genes of Pseudomonas sp. strain HR199 involved in bioconversion of vanillin to protocatechuate. J Bacteriol 1997, 179(8):2595-2607.

60. Adachi O, Tanasupawat S, Yoshihara N, Toyama H, Matsushita K: 3Dehydroquinate production by oxidative fermentation and further conversion of 3-dehydroquinate to the intermediates in the shikimate pathway. Biosci Biotechnol Biochem 2003, 67(10):2124-2131.

61. Herrmann KM, Weaver LM: The shikimate pathway. Annu Rev Plant Physiol Plant Mol Biol 1999, 50:473-503.

62. Essar DW, Eberly L, Hadero A, Crawford IP: Identification and characterization of genes for a second anthranilate synthase in Pseudomonas aeruginosa: interchangeability of the two anthranilate synthases and evolutionary implications. J Bacteriol 1990, 172(2):884-900

63. Liu W, Christenson SD, Standage S, Shen B: Biosynthesis of the enediyne antitumor antibiotic C-1027. Science 2002, 297(5584):1170-1173.

64. Serre L, Sailland A, Sy D, Boudec P, Rolland A, Pebay-Peyroula E, CohenAddad C: Crystal structure of Pseudomonas fluorescens 4hydroxyphenylpyruvate dioxygenase: an enzyme involved in the tyrosine degradation pathway. Structure 1999, 7(8):977-988.

65. Arias-Barrau E, Olivera ER, Luengo JM, Fernández C, Galán B, García JL, Díaz E, Miñambres B: The homogentisate pathway: a central catabolic pathway involved in the degradation of L-phenylalanine, L-tyrosine, and 3-hydroxyphenylacetate in Pseudomonas putida. J Bacteriol 2004, 186 (15):5062-5077.

66. Sparnins VL, Chapman PJ: Catabolism of L-tyrosine by the homoprotocatechuate pathway in Gram-positive bacteria. J Bacteriol 1976, 127(1):362-366.

67. Barbour MG, Bayly RC: Control of meta-cleavage degradation of 4hydroxyphenylacetate in Pseudomonas putida. J Bacteriol 1981, 147(3):844-850.

68. Roper DI, Cooper RA: Subcloning and nucleotide sequence of the 3,4dihydroxyphenylacetate (homoprotocatechuate) 2,3-dioxygenase gene from Escherichia coli C. FEBS Lett 1990, 275(1-2):53-57.

69. Gibello A, Ferrer E, Martin M, Garrido-Pertierra A: 3, 4Dihydroxyphenylacetate 2, 3-dioxygenase from Klebsiella pneumoniae, a $\mathrm{Mg}(2+)$-containing dioxygenase involved in aromatic catabolism. Biochem J 1994, 301(Pt 1):145.

70. Vetting MW, Wackett LP, Que L Jr, Lipscomb JD, Ohlendorf DH: Crystallographic comparison of manganese- and iron-dependent homoprotocatechuate 2,3-dioxygenases. J Bacterio/ 2004, 186(7):1945-1958.

71. Lipscomb JD: Mechanism of extradiol aromatic ring-cleaving dioxygenases. Curr Opin Struct Biol 2008, 18(6):644-649.

72. Hanlon SP, Hill TK, Flavell MA, Stringfellow JM, Cooper RA: 2Phenylethylamine catabolism by Escherichia coli K-12: gene organization and expression. Microbiology 1997, 143:513-518.

73. Sun D, Ono K, Okajima T, Tanizawa K, Uchida M, Yamamoto Y, Mathews FS, Davidson VL: Chemical and kinetic reaction mechanisms of quinohemoprotein amine dehydrogenase from Paracoccus denitrificans. Biochemistry 2003, 42(37):10896-10903.

74. Arias S, Olivera ER, Arcos M, Naharro G, Luengo JM: Genetic analyses and molecular characterization of the pathways involved in the conversion of 2-phenylethylamine and 2-phenylethanol into phenylacetic acid in Pseudomonas putida U. Environ Microbiol 2008, 10(2):413-432.

75. Olivera ER, Minambres B, Garcia B, Muniz C, Moreno MA, Ferrandez A, Diaz E, Garcia JL, Luengo JM: Molecular characterization of the phenylacetic acid catabolic pathway in Pseudomonas putida U: the phenylacetyl-CoA catabolon. Proc Natl Acad Sci U S A 1998, 95(11):6419-6424.

76. Luengo JM, Garcia JL, Olivera ER: The phenylacetyl-CoA catabolon: a complex catabolic unit with broad biotechnological applications. $\mathrm{Mo}$ Microbiol 2001, 39(6):1434-1442.

77. Parales RE, Resnick SM: Aromatic ring hydroxylating dioxygenases. Pseudomonas 2006, 287:287-340.

78. Bertin $C$, Yang $X$, Weston LA: The role of root exudates and allelochemicals in the rhizosphere. Plant Soil 2003, 256(1):67-83.

79. Lugtenberg B, Kamilova F: Plant-growth-promoting rhizobacteria. Annu Rev Microbioz 2009, 63(1):541-556.

80. Van Gundy SD, Kirkpatrick JD, Golden J: The nature and role of metabolic leakage from root-knot nematode galls and infection by Rhizoctonia solani. J Nematol 1977, 9(2):113-121.

81. Kamilova F, Lamers G, Lugtenberg B: Biocontrol strain Pseudomonas fluorescens WCS365 inhibits germination of Fusarium oxysporum spores in tomato root exudate as well as subsequent formation of new spores. Environ Microbiol 2008, 10(9):2455-2461.

82. Mark GL, Dow JM, Kiely PD, Higgins H, Haynes J, Baysse C, Abbas A, Foley T, Franks A, Morrissey J, O'Gara F: Transcriptome profiling of bacterial responses to root exudates identifies genes involved in microbe-plant interactions. Proc Natl Acad Sci U S A 2005, 102(48):17454-17459.

83. Roy-Burman A, Savel RH, Racine S, Swanson BL, Revadigar NS, Fujimoto J, Sawa T, Frank DW, Wiener-Kronish JP: Type III protein secretion is associated with death in lower respiratory and systemic Pseudomonas aeruginosa infections. J Infect Dis 2001, 183(12):1767-1774.

84. Hoshino N, Kimura T, Yamaji A, Ando T: Damage to the cytoplasmic membrane of Escherichia coli by catechin-copper (II) complexes. Free Radic Biol Med 1999, 27(11-12):1245-1250.

85. Nies DH: Efflux-mediated heavy metal resistance in prokaryotes. FEMS Microbiol Rev 2003, 27(2-3):313-339.

86. Mejare M, Bulow L: Metal-binding proteins and peptides in bioremediation and phytoremediation of heavy metals. Trends Biotechnol 2001, 19(2):67-73.

87. Vuilleumier S, Pagni M: The elusive roles of bacterial glutathione Stransferases: new lessons from genomes. Appl Microbiol Biotechnol 2002, 58(2):138-146.

88. Cha JS, Cooksey DA: Copper resistance in Pseudomonas syringae mediated by periplasmic and outer membrane proteins. Proc Natl Acad Sci U S A 1991, 88(20):8915-8919.

89. Zhang X, Rainey PB: Regulation of copper homeostasis in Pseudomonas fluorescens SBW25. Environ Microbiol 2008, 10(12):3284-3294.

90. Rae TD, Schmidt PJ, Pufahl RA, Culotta VC, O'Halloran TV: Undetectable intracellular free copper: the requirement of a copper chaperone for superoxide dismutase. Science 1999, 284(5415):805-808.

91. Changela A, Chen K, Xue Y, Holschen J, Outten CE, O'Halloran TV, Mondragon A: Molecular basis of metal-ion selectivity and zeptomolar sensitivity by CueR. Science 2003, 301(5638):1383-1387.

92. Rensing C, Fan B, Sharma R, Mitra B, Rosen BP: CopA: an Escherichia coli Cu (I)-translocating P-type ATPase. Proc Natl Acad Sci U S A 2000, 97(2):652-656

93. Roberts SA, Weichsel A, Grass G, Thakali K, Hazzard JT, Tollin G, Rensing C, Montfort WR: Crystal structure and electron transfer kinetics of CueO, a multicopper oxidase required for copper homeostasis in Escherichia coli. Proc Natl Acad Sci U S A 2002, 99(5):2766-2771.

94. Franke S, Grass G, Rensing C, Nies DH: Molecular analysis of the coppertransporting efflux system CusCFBA of Escherichia coli. J Bacteriol 2003 185(13):3804-3812.

95. Pontel LB, Soncini FC: Alternative periplasmic copper-resistance mechanisms in Gram-negative bacteria. Mol Microbiol 2009, 73(2):212-225.

96. Cai J, Salmon K, DuBow MS: A chromosomal ars operon homologue of Pseudomonas aeruginosa confers increased resistance to arsenic and antimony in Escherichia coli. Microbiology 1998, 144(Pt 10):2705-2713.

97. Dey S, Rosen BP: Dual mode of energy coupling by the oxyaniontranslocating ArsB protein. J Bacteriol 1995, 177(2):385-389.

98. Nies DH: The cobalt, zinc, and cadmium efflux system CzcABC from Alcaligenes eutrophus functions as a cation-proton antiporter in Escherichia coli. J Bacteriol 1995, 177(10):2707-2712.

99. Pimentel BE, Moreno-Sanchez R, Cervantes C: Efflux of chromate by Pseudomonas aeruginosa cells expressing the ChrA protein. FEMS Microbiol Lett 2002, 212(2):249-254. 
100. Schalk IJ, Hannauer M, Braud A: New roles for bacterial siderophores in metal transport and tolerance. Environ Microbiol 2011, 13(11):2844-2854.

101. Xavier D, Picão R, Girardello R, Fehlberg L, Gales A: Efflux pumps expression and its association with porin down-regulation and $\beta$ lactamase production among Pseudomonas aeruginosa causing bloodstream infections in Brazil. BMC Microbiol 2010, 10(1):217.

102. Alekshun MN, Levy SB: Molecular mechanisms of antibacterial multidrug resistance. Cell 2007, 128(6):1037-1050.

103. Poole K: Efflux-mediated multiresistance in Gram-negative bacteria. Clin Microbiol Infect 2004, 10(1):12-26.

104. Georgopapadakou NH: Penicillin-binding proteins and bacterial resistance to beta-lactams. Antimicrob Agents Chemother 1993, 37(10):2045-2053.

105. Saier MH Jr, Paulsen IT: Phylogeny of multidrug transporters. Semin Cell Dev Biol 2001, 12(3):205-213.

106. Mosqueda $G$, Ramos $J$ : A set of genes encoding a second toluene efflux system in Pseudomonas putida DOT-T1E is linked to the tod genes for toluene metabolism. J Bacterio/ 2000, 182(4):937-943.

107. Fetar H, Gilmour C, Klinoski R, Daigle DM, Dean CR, Poole K: mexEF-oprN multidrug efflux operon of Pseudomonas aeruginosa: regulation by the MexT activator in response to nitrosative stress and chloramphenicol. Antimicrob Agents Chemother 2011, 55(2):508-514.

108. Kohler T, van Delden C, Curty LK, Hamzehpour MM, Pechere JC: Overexpression of the MexEF-OprN multidrug efflux system affects cellto-cell signaling in Pseudomonas aeruginosa. J Bacteriol 2001, 183 (18):5213-5222.

109. Takatsuka Y, Chen C, Nikaido H: Mechanism of recognition of compounds of diverse structures by the multidrug efflux pump AcrB of Escherichia coli. Proc Natl Acad Sci U S A 2010, 107(15):6559-6565.

110. Ma D, Alberti M, Lynch C, Nikaido H, Hearst JE: The local repressor AcrR plays a modulating role in the regulation of $a c r A B$ genes of Escherichia coli by global stress signals. Mol Microbiol 1996, 19(1):101-112.

111. Foreman J, Demidchik V, Bothwell JHF, Mylona P, Miedema H, Torres MA, Linstead P, Costa S, Brownlee C, Jones JDG, Davies JM, Dolan L: Reactive oxygen species produced by NADPH oxidase regulate plant cell growth. Nature 2003, 422(6930):442-446.

112. Bolwell G, Wojtaszek P: Mechanisms for the generation of reactive oxygen species in plant defence - a broad perspective. Physiol Molec Plant Pathol 1997, 51(6):347-366.

113. Storz G, Imlay JA: Oxidative stress. Curr Opin Microbio/ 1999, 2(2):188-194.

114. Whistler CA, Corbell NA, Sarniguet A, Ream W, Loper JE: The twocomponent regulators GacS and GacA influence accumulation of the stationary-phase sigma factor $\sigma^{\mathrm{S}}$ and the stress response in Pseudomonas fluorescens Pf-5. J Bacteriol 1998, 180(24):6635-6641.

115. Ochsner UA, Vasil ML, Alsabbagh E, Parvatiyar K, Hassett DJ: Role of the Pseudomonas aeruginosa oxyR-recG operon in oxidative stress defense and DNA repair: OxyR-dependent regulation of katB-ankB, ahpB, and ahpC-ahpF. J Bacteriol 2000, 182(16):4533-4544.

116. Palma M, Zurita J, Ferreras JA, Worgall S, Larone DH, Shi L, Campagne F, Quadri LE: Pseudomonas aeruginosa SoxR does not conform to the archetypal paradigm for SoxR-dependent regulation of the bacterial oxidative stress adaptive response. Infect Immun 2005, 73(5):2958-2966.

117. Chang WS, Li X, Halverson L: Influence of water limitation on endogenous oxidative stress and cell death within unsaturated Pseudomonas putida biofilms. Environ Microbiol 2009, 11(6):1482-1492.

118. Fones $H$, Preston GM: Reactive oxygen and oxidative stress tolerance in plant pathogenic Pseudomonas. FEMS Microbiol Lett 2012, 327(1):1-8.

119. Ayub ND, Tribelli PM, Lopez NI: Polyhydroxyalkanoates are essential for maintenance of redox state in the Antarctic bacterium Pseudomonas sp. 14-3 during low temperature adaptation. Extremophiles 2009, 13(1):59-66.

120. Castro-Sowinski S, Burdman S, Matan O, Okon Y: Natural functions of bacterial polyhydroxyalkanoates. In Plastics from Bacteria. Edited by Chen GGQ. Berlin/Heidelberg: Springer; 2010:39-61.

121. Khairnar NP, Misra HS, Apte SK: Pyrroloquinoline-quinone synthesized in Escherichia coli by pyrroloquinoline-quinone synthase of Deinococcus radiodurans plays a role beyond mineral phosphate solubilization. Biochem Biophys Res Commun 2003, 312(2):303-308.

122. Ramos JL, Gallegos MT, Marques S, Ramos-Gonzalez MI, Espinosa-Urgel M, Segura A: Responses of Gram-negative bacteria to certain environmental stressors. Curr Opin Microbiol 2001, 4(2):166-171.

123. Ermolenko DN, Makhatadze Gl: Bacterial cold-shock proteins. Cell Mol Life Sci 2002, 59(11):1902-1913.
124. Allan B, Linseman M, MacDonald LA, Lam JS, Kropinski AM: Heat shock response of Pseudomonas aeruginosa. J Bacteriol 1988, 170(8):3668-3674.

125. Gamer J, Multhaup G, Tomoyasu T, McCarty JS, Rudiger S, Schonfeld HJ, Schirra C, Bujard H, Bukau B: A cycle of binding and release of the DnaK, DnaJ and GrpE chaperones regulates activity of the Escherichia coli heat shock transcription factor sigma32. EMBO J 1996, 15(3):607-617.

126. Csonka LN: Physiological and genetic responses of bacteria to osmotic stress. Microbiol Rev 1989, 53(1):121-147.

127. Aspedon A, Palmer K, Whiteley M: Microarray analysis of the osmotic stress response in Pseudomonas aeruginosa. J Bacteriol 2006 188(7):2721-2725.

128. Brown AD: Microbial water stress. Bacteriol Rev 1976, 40(4):803-846.

129. Wargo MJ, Szwergold BS, Hogan DA: Identification of two gene clusters and a transcriptional regulator required for Pseudomonas aeruginosa glycine betaine catabolism. J Bacteriol 2008, 190(8):2690-2699.

130. Styrvold OB, Falkenberg P, Landfald B, Eshoo MW, Bjornsen T, Strom AR: Selection, mapping, and characterization of osmoregulatory mutants of Escherichia coli blocked in the choline-glycine betaine pathway. J Bacteriol 1986, 165(3):856-863.

131. Lequette $Y$, Odberg-Ferragut C, Bohin JP, Lacroix JM: Identification of $m d o D$, an $m d o G$ paralog which encodes a twin-arginine-dependent periplasmic protein that controls osmoregulated periplasmic glucan backbone structures. J Bacterio/ 2004, 186(12):3695-3702.

132. Miller KJ, Wood JM: Osmoadaptation by rhizosphere bacteria. Annu Rev Microbiol 1996, 50:101-136

133. Booth IR, Higgins CF: Enteric bacteria and osmotic stress: intracellular potassium glutamate as a secondary signal of osmotic stress? FEMS Microbiol Rev 1990, 6(2-3):239-246.

134. Bolwerk A, Lagopodi AL, Wijfjes AH, Lamers GE, Chin AWTF, Lugtenberg BJ, Bloemberg GV: Interactions in the tomato rhizosphere of two Pseudomonas biocontrol strains with the phytopathogenic fungus Fusarium oxysporum f. sp. radicis-lycopersici. Mol Plant Microbe Interact 2003, 16(11):983-993.

135. Lugtenberg BJ, Dekkers L, Bloemberg GV: Molecular determinants of rhizosphere colonization by Pseudomonas. Annu Rev Phytopathol 2001, 39:461-490

136. Kiely PD, Haynes JM, Higgins CH, Franks A, Mark GL, Morrissey JP, O'Gara F: Exploiting new systems-based strategies to elucidate plant-bacterial interactions in the rhizosphere. Microb Ecol 2006, 51(3):257-266.

137. Boyd A, Simon M: Bacterial chemotaxis. Annu Rev Physiol 1982, 44(1):501-517.

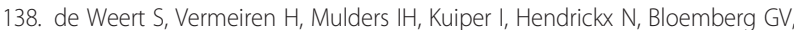
Vanderleyden J, De Mot R, Lugtenberg BJ: Flagella-driven chemotaxis towards exudate components is an important trait for tomato root colonization by Pseudomonas fluorescens. Mol Plant Microbe Interact 2002, 15(11):1173-1180.

139. Wadhams GH, Armitage JP: Making sense of it all: bacterial chemotaxis. Nat Rev Mol Cell Biol 2004, 5(12):1024-1037.

140. Barak R, Eisenbach M: Correlation between phosphorylation of the chemotaxis protein $\mathrm{CheY}$ and its activity at the flagellar motor. Biochemistry 1992, 31(6):1821-1826.

141. Wall D, Kaiser D: Type IV pili and cell motility. Mol Microbio/ 1999 32(1):1-10.

142. Bianciotto V, Andreotti S, Balestrini R, Bonfante P, Perotto S: Mucoid mutants of the biocontrol strain Pseudomonas fluorescens $\mathrm{CHAO}$ show increased ability in biofilm formation on mycorrhizal and nonmycorrhizal carrot roots. Mol Plant Microbe Interact 2001, 14(2):255-260.

143. Espinosa-Urgel M, Salido A, Ramos JL: Genetic analysis of functions involved in adhesion of Pseudomonas putida to seeds. J Bacteriol 2000, 182(9):2363-2369.

144. Rojas CM, Ham JH, Deng WL, Doyle JJ, Collmer A: HecA, a member of a class of adhesins produced by diverse pathogenic bacteria, contributes to the attachment, aggregation, epidermal cell killing, and virulence phenotypes of Erwinia chrysanthemi EC16 on Nicotiana clevelandii seedlings. Proc Natl Acad Sci U S A 2002, 99(20):13142-13147.

145. Dekkers LC, van der Bij AJ, Mulders IH, Phoelich CC, Wentwoord RA, Glandorf DC, Wijffelman CA, Lugtenberg BJ: Role of the O-antigen of lipopolysaccharide, and possible roles of growth rate and of $\mathrm{NADH}$ ubiquinone oxidoreductase (nuo) in competitive tomato root-tip colonization by Pseudomonas fluorescens WCS365. Mol Plant Microbe Interact 1998, 11(8):763-771. 
146. Tomich M, Planet PJ, Figurski DH: The tad locus: postcards from the widespread colonization island. Nat Rev Microbiol 2007, 5(5):363-375

147. O'Connell Motherway M, Zomer A, Leahy SC, Reunanen J, Bottacini F, Claesson MJ, O'Brien F, Flynn K, Casey PG, Munoz JA, Kearney B, Houston AM, O'Mahony C, Higgins DG, Shanahan F, Palva A, de Vos WM, Fitzgerald GF, Ventura M, O'Toole PW, van Sinderen D: Functional genome analysis of Bifidobacterium breve UCC2003 reveals type IVb tight adherence (Tad) pili as an essential and conserved host-colonization factor. Proc Natl Acad Sci U S A 2011, 108(27):11217-11222.

148. Ramos-Gonzalez MI, Campos MJ, Ramos JL: Analysis of Pseudomonas putida KT2440 gene expression in the maize rhizosphere: in vivo expression technology capture and identification of root-activated promoters. J Bacteriol 2005, 187(12):4033-4041.

149. Buell CR, Anderson AJ: Genetic analysis of the aggA locus involved in agglutination and adherence of Pseudomonas putida, a beneficial fluorescent pseudomonad. Mol Plant Microbe Interact 1992, 5(2):154-162.

150. Dekkers LC, Phoelich CC, van der Fits L, Lugtenberg BJ: A site-specific recombinase is required for competitive root colonization by Pseudomonas fluorescens WCS365. Proc Natl Acad Sci U S A 1998 95(12):7051-7056.

151. Gal M, Preston GM, Massey RC, Spiers AJ, Rainey PB: Genes encoding a cellulosic polymer contribute toward the ecological success of Pseudomonas fluorescens SBW25 on plant surfaces. Mol Ecol 2003, 12(11):3109-3121.

152. Bender CL, Alarcon-Chaidez F, Gross DC: Pseudomonas syringae phytotoxins: mode of action, regulation, and biosynthesis by peptide and polyketide synthetases. Microbiol Mol Biol Rev 1999, 63(2):266-292.

153. Mavrodi DV, Peever TL, Mavrodi OV, Parejko JA, Raaijmakers JM, Lemanceau P, Mazurier S, Heide L, Blankenfeldt W, Weller DM, Thomashow LS: Diversity and evolution of the phenazine biosynthesis pathway. Appl Environ Microbiol 2010, 76(3):866-879.

154. Delaney SM, Mavrodi DV, Bonsall RF, Thomashow LS: phzO, a gene for biosynthesis of 2-hydroxylated phenazine compounds in Pseudomonas aureofaciens 30-84. J Bacteriol 2001, 183(1):318-327.

155. Parsons JF, Greenhagen BT, Shi K, Calabrese K, Robinson H, Ladner JE: Structural and functional analysis of the pyocyanin biosynthetic protein PhzM from Pseudomonas aeruginosa. Biochemistry 2007, 46(7):1821-1828.

156. Pechy-Tarr M, Bruck DJ, Maurhofer M, Fischer E, Vogne C, Henkels MD, Donahue KM, Grunder J, Loper JE, Keel C: Molecular analysis of a novel gene cluster encoding an insect toxin in plant-associated strains of Pseudomonas fluorescens. Environ Microbiol 2008, 10(9):2368-2386.

157. Daborn PJ, Waterfield N, Silva CP, Au CP, Sharma S, Ffrench-Constant RH: A single Photorhabdus gene, makes caterpillars floppy (mcf), allows Escherichia coli to persist within and kill insects. Proc Natl Acad Sci U S A 2002, 99(16):10742-10747.

158. Meyer JM: Pyoverdines: pigments, siderophores and potential taxonomic markers of fluorescent Pseudomonas species. Arch Microbiol 2000, 174(3):135-142.

159. Kloepper JW, Leong J, Teintze M, Schroth MN: Enhanced plant growth by siderophores produced by plant growth-promoting rhizobacteria. Nature 1980, 286(5776):885-886.

160. Phoebe CH Jr, Combie J, Albert FG, Van Tran K, Cabrera J, Correira HJ, Guo Y, Lindermuth J, Rauert N, Galbraith W, Selitrennikoff CP: Extremophilic orgainisms as an unexplored source of antifungal compounds. J Antibiot 2001, 54(1):56-65.

161. Franza T, Mahe B, Expert D: Erwinia chrysanthemi requires a second iron transport route dependent of the siderophore achromobactin for extracellular growth and plant infection. Mol Microbio/ 2005, 55(1):261-275

162. Owen JG, Ackerley DF: Characterization of pyoverdine and achromobactin in Pseudomonas syringae pv. phaseolicola 1448a. BMC Microbiol 2011, 11:218.

163. Cornelis P: Iron uptake and metabolism in pseudomonads. App/ Microbiol Biotechnol 2010, 86(6):1637-1645.

164. Mithani A, Hein J, Preston GM: Comparative analysis of metabolic networks provides insight into the evolution of plant pathogenic and nonpathogenic lifestyles in Pseudomonas. Mol Biol Evol 2010, 28(1):483-499.

165. Vessey KJ: Plant growth promoting rhizobacteria as biofertilizers. Plant Soil 2003, 255:571-586
166. Roberts GP, MacNeil T, MacNeil D, Brill WJ: Regulation and characterization of protein products coded by the nif (nitrogen fixation) genes of Klebsiella pneumoniae. J Bacteriol 1978, 136(1):267-279.

167. Yan Y, Ping S, Peng J, Han Y, Li L, Yang J, Dou Y, Li Y, Fan H, Fan Y, Li D, Zhan Y, Chen M, Lu W, Zhang W, Cheng Q, Jin Q, Lin M: Global transcriptional analysis of nitrogen fixation and ammonium repression in root-associated Pseudomonas stutzeri A1501. BMC Genomics 2010, 11:11.

168. Stewart V, Parales J Jr: Identification and expression of genes narL and narX of the nar (nitrate reductase) locus in Escherichia coli K-12. J Bacteriol 1988, 170(4):1589-1597.

169. Greenberg EP, Becker GE: Nitrous oxide as end product of denitrification by strains of fluorescent pseudomonads. Can J Microbiol 1977, 23(7):903-907.

170. Carlson CA, Ingraham JL: Comparison of denitrification by Pseudomonas stutzeri, Pseudomonas aeruginosa, and Paracoccus denitrificans. Appl Environ Microbiol 1983, 45(4):1247-1253.

171. Seitzinger SP: Denitrification in freshwater and coastal marine ecosystems: ecological and geochemical significance. Limnol Oceanogr 1988:702-724

172. Rodriguez $H$, Fraga R: Phosphate solubilizing bacteria and their role in plant growth promotion. Biotechnol Adv 1999, 17(4-5):319-339.

173. Palm CJ, Gaffney T, Kosuge T: Cotranscription of genes encoding indoleacetic acid production in Pseudomonas syringae subsp. savastanoi. J Bacteriol 1989, 171(2):1002-1009.

174. Wang C, Knill E, Glick BR, Defago G: Effect of transferring 1aminocyclopropane-1-carboxylic acid (ACC) deaminase genes into Pseudomonas fluorescens strain $\mathrm{CHAO}$ and its gacA derivative $\mathrm{CHA96}$ on their growth-promoting and disease-suppressive capacities. Can J Microbiol 2000, 46(10):898-907.

175. Choi O, Kim J, Kim JG, Jeong Y, Moon JS, Park CS, Hwang I: Pyrroloquinoline quinone is a plant growth promotion factor produced by Pseudomonas fluorescens B16. Plant Physiol 2008, 146(2):657-668.

176. Toyama $\mathrm{H}$, Lidstrom ME: $p q q A$ is not required for biosynthesis of pyrroloquinoline quinone in Methylobacterium extorquens AM1. Microbiology 1998, 144(Pt 1):183-191.

177. King EO, Ward MK, Raney DE: Two simple media for the demonstration of pyocyanin and fluorescin. J lab clin Med 1954, 44(2):301-307.

178. Aziz RK, Bartels D, Best AA, DeJongh M, Disz T, Edwards RA, Formsma K, Gerdes S, Glass EM, Kubal M, Meyer F, Olsen GJ, Olson R, Osterman AL, Overbeek RA, McNeil LK, Paarmann D, Paczian T, Parrello B, Pusch GD, Reich C, Stevens R, Vassieva O, Vonstein V, Wilke A, Zagnitko O: The RAST server: rapid annotations using subsystems technology. BMC Genomics 2008, 9:75.

179. Markowitz VM, Mavromatis K, Ivanova NN, Chen IM, Chu K, Kyrpides NC: IMG ER: a system for microbial genome annotation expert review and curation. Bioinformatics 2009, 25(17):2271-2278.

180. Kanehisa M, Araki M, Goto S, Hattori M, Hirakawa M, Itoh M, Katayama T, Kawashima S, Okuda S, Tokimatsu T, Yamanishi Y: KEGG for linking genomes to life and the environment. Nucleic Acids Res 2008, 36(Database issue):480-484

181. Caspi R, Altman T, Dreher K, Fulcher CA, Subhraveti P, Keseler IM, Kothari A, Krummenacker M, Latendresse M, Mueller LA, Ong Q, Paley S, Pujar A, Shearer AG, Travers M, Weerasinghe D, Zhang P, Karp PD: The MetaCyc database of metabolic pathways and enzymes and the BioCyc collection of pathway/genome databases. Nucleic Acids Res 2012, 40(Database issue):742-753

182. Thompson JD, Higgins DG, Gibson TJ: CLUSTAL W: improving the sensitivity of progressive multiple sequence alignment through sequence weighting, position-specific gap penalties and weight matrix choice. Nucleic Acids Res 1994, 22(22):4673-4680

183. Saitou N, Nei M: The neighbor-joining method: a new method for reconstructing phylogenetic trees. Mol Biol Evol 1987, 4(4):406-425

184. Letunic I, Bork P: Interactive tree of life (iTOL): an online tool for phylogenetic tree display and annotation. Bioinformatics 2007, 23(1):127-128

doi:10.1186/1471-2164-14-271

Cite this article as: Shen et al:: Comparative genomic analysis of four representative plant growth-promoting rhizobacteria in Pseudomonas. BMC Genomics 2013 14:271. 